Revue des patrimoines

\title{
Les temples protestants « monuments historiques » en Poitou-Charentes
}

\section{Brigitte Montagne, Yannick Comte et Catherine Tijou}

\section{(2) OpenEdition}

Journals

Édition électronique

URL : http://journals.openedition.org/insitu/4893

DOI : 10.4000/insitu.4893

ISSN : 1630-7305

\section{Éditeur}

Ministère de la culture

Référence électronique

Brigitte Montagne, Yannick Comte et Catherine Tijou, « Les temples protestants « monuments historiques » en Poitou-Charentes », In Situ [En ligne], 11 | 2009, mis en ligne le 18 avril 2012, consulté le 19 avril 2019. URL : http://journals.openedition.org/insitu/4893 ; DOI : 10.4000/insitu.4893

Ce document a été généré automatiquement le 19 avril 2019

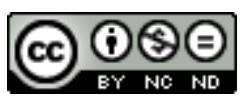

In Situ Revues des patrimoines est mis à disposition selon les termes de la licence Creative Commons Attribution - Pas d'Utilisation Commerciale - Pas de Modification 4.0 International. 


\title{
Les temples protestants " monuments historiques » en Poitou-Charentes
}

\author{
Brigitte Montagne, Yannick Comte et Catherine Tijou
}

1 Si l'histoire du protestantisme en Poitou-Charentes a donné lieu à une littérature abondante ${ }^{1}$, l'étude du patrimoine protestant n'a pas, en revanche, intéressé autant les auteurs ${ }^{2}$. Forte de ce constat, la conservation régionale des monuments historiques a saisi l'opportunité de la commémoration de l'édit de Nantes (signé le 30 avril 1598) pour poser un regard particulier sur l'architecture des temples (re)construits pour la plupart au cours du XIX ${ }^{e}$ siècle et pour certains au XXe siècle. Ainsi, le 27 mai 1998, une séance de la commission régionale du patrimoine historique, archéologique et ethnologique (CO.RE.P.H.A.E.) a été entièrement consacrée à cette thématique permettant d'introduire des éléments de ce patrimoine dans la liste des monuments protégés.

\section{Un rappel du contexte régional ${ }^{3}$}

2 La propagation de la Réforme protestante se fait très rapidement en Aunis, Saintonge et dans le Poitou, tout comme en Bretagne et en Anjou. Entre la présence de Luther en Allemagne en 1517 et la naissance de Catherine de Parthenay en 1554, trois générations de protestants se sont déjà succédé. C'est dire que les idées, se propagent très vite et que les événements se précipitent pour ceux que l'on appelait les huguenots, voire «la vermine luthérienne ».

En 1534, Calvin est à Poitiers et les idées de la Réforme vont trouver une large audience auprès du monde de l'université puis, avec les voyageurs, les colporteurs et surtout l'imprimerie, une plus large diffusion encore auprès des artisans et des commerçants. Dès l'origine, les foyers les plus fervents vont se situer à Angoulême, Cognac, Saintes et SaintJean-d'Angély, la presqu'île d'Arvert, Marennes, Saujon, Pons, La Rochelle, Saint-Martinde-Ré ainsi qu'à Poitiers et Loudun. Le Poitou, pris en tenaille entre Tours et Amboise, la haute Bretagne et le Béarn gagnés à la Réforme, sera un des hauts lieux de la propagation 
du protestantisme, des guerres de Religion et de leurs conséquences. La soumission de La Rochelle, le 28 octobre 1628, marque la fin du protestantisme militaire. Cependant, les seigneurs cultivés et voyageurs pour la guerre ou le loisir, entraînant leur entourage et leur domesticité, les élites et les commerçants, vont concourir à entretenir la vitalité du protestantisme de l'Ouest, en relation avec les Pays-Bas, l'Allemagne et l'Angleterre.

Malgré l'exil massif qui a suivi la Révocation en 1685, la présence protestante dans la région reste forte jusqu'à la Révolution. Les protestants obtiennent la liberté d'état civil en 1787. La liberté officieuse du culte, établie en 1789, devient officielle en 1795 et est confirmée en 1905. Au cours du $\mathrm{XIX}^{\mathrm{e}}$ siècle, des colporteurs et des évangélistes participent à la renaissance de ce culte dans toute la région.

Figure 1

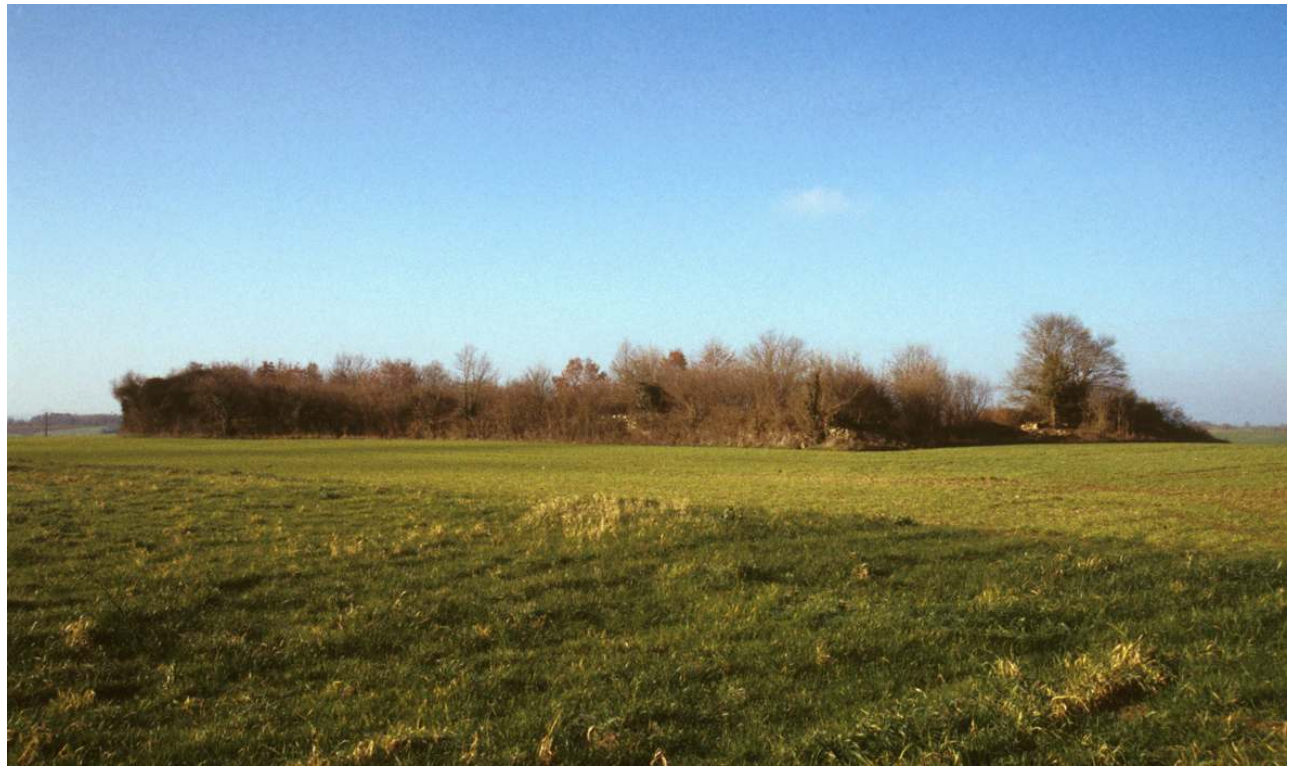

Villefagnan (Charente). Lieudit les Communes, lieu d'assemblées du désert (C) CRMH Poitou-Charentes, 1998

5 Après le décret impérial du 5 mai 1806 autorisant les protestants à avoir des lieux de culte, les communautés du Poitou et des Charentes, sortant de plus d'un siècle $\mathrm{d}^{\prime}$ '«assemblée du désert " (fig. $\mathbf{n}^{\circ} \mathbf{1}$ ), vont se maintenir là où elles étaient le mieux implantées depuis l'origine.

Le Poitou compte alors plus de 30000 protestants, répartis essentiellement dans les DeuxSèvres, entre Melle et Niort, avec quelques centres isolés vers Moncoutant et un peu dans la Vienne ${ }^{4}$. Dans certains secteurs, la moitié de la population est calviniste et une dizaine de communes ne compte même aucun catholique. Le foyer le plus important est ensuite celui de la presqu'île d'Arvert, autour de Marennes en Charente-Maritime avec quelques communautés en Charente entre Jarnac et Saintes, estimées à 20000 fidèles. La Rochelle, tout comme le port de Nantes, compte encore parmi les centres protestants les plus importants.

7 Les nouveaux pasteurs nommés dans la région n'accordent que peu d'importance à la construction de temples, utilisant à l'occasion des granges ou des églises désaffectées. Par ailleurs, les nouvelles constructions souffrent vite du manque d'entretien. 
8 De plus, petit à petit, au cours du XIX ${ }^{\mathrm{e}}$ siècle, le culte protestant, de rural qu'il était, se déplace vers les milieux urbains, suivant les «élites» instruites, en partie par la lecture de la Bible, qui vont jouer un rôle actif dans l'industrie, le commerce ou la fonction publique.

\section{Le cas particulier des maisons d'oraison}

9 La Charente possède une particularité, que l'on retrouve aussi en Charente-Maritime mais semble-t-il de manière moins sensible : les maisons d'oraison.

10 En effet, après la démolition systématique des temples à la fin du XVII ${ }^{e}$ siècle, souvent d'ailleurs quelques années même avant la Révocation de l'édit de $\mathrm{Nantes}^{5}$, on voit apparaître dans la deuxième moitié du XVIII ${ }^{\mathrm{e}}$ siècle des maisons d'oraison, granges utilisées pour le culte, dont l'aspect anodin assurait la discrétion des réunions de réformés et permettait, en cas de danger, une fuite rapide.

11 La tenue d'assemblées, illicites, devient alors possible, la politique royale à l'égard des protestants s'infléchissant: même si la loi ne change pas et reste tout aussi sévère, son application est de plus en plus rare ; ainsi, dans tout l'Angoumois, la royauté n'intervient plus contre les réformés à partir de 1760, soit trente ans avant l'édit de tolérance.

12 Parmi ces maisons d'oraison, on peut citer en Angoumois celle de Jarnac, qui est construite en 1761 par M. Ranson de Bois-Blanchard à la place d'une grange agrandie en 1820-1823 et réaménagée en 1886-1688, c'est le temple actuel ${ }^{6}$, seul exemple de la région de réutilisation d'une maison d'oraison.

13 À Segonzac, une vaste grange appartenant à un riche bourgeois calviniste, M. Guesdon, sert de lieu de réunion. Cette maison d'oraison est transformée en temple et utilisée jusqu'en 1866, date à laquelle elle fait place au nouveau temple (temple actuel), édifié par l'architecte Demenieux (activité connue de 1855 à 1866) sur la même parcelle7. 


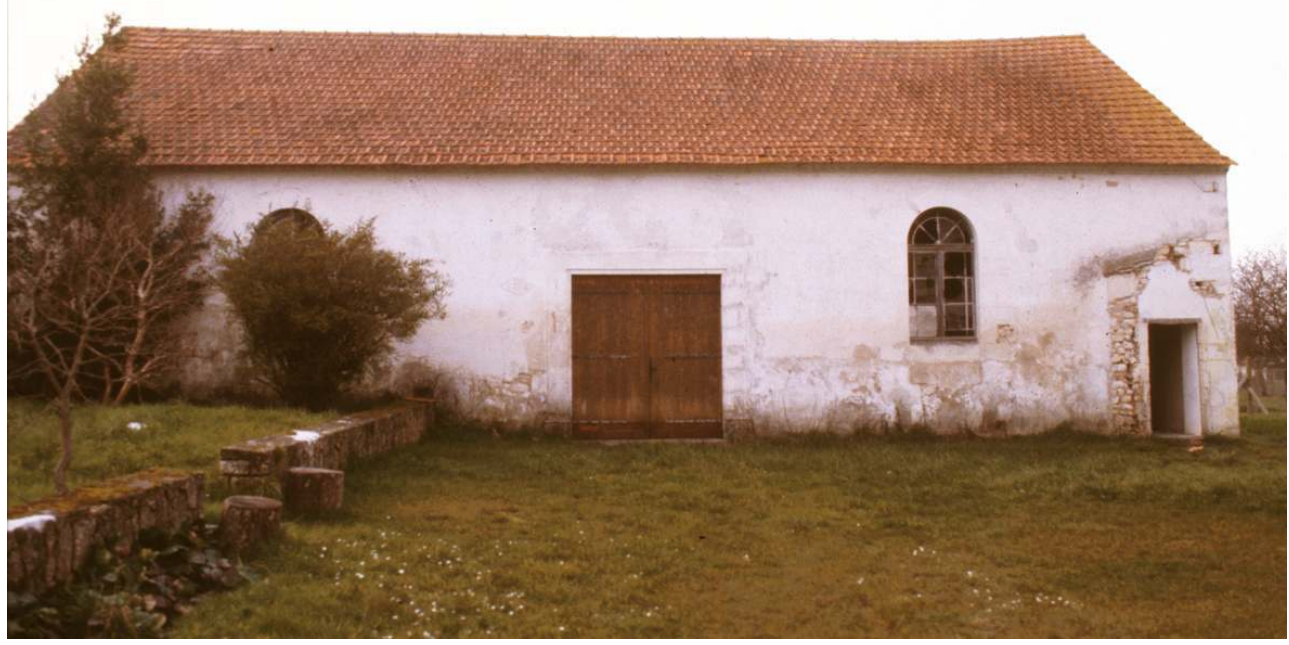

Arvert (Charente-Maritime). Lieudit Avallon. Ancienne maison d'oraison

(C) CRMH Poitou-Charentes, 1994

14 À Villefagnan, une grange cédée aux protestants par la famille Rousseau est aménagée et transformée (baies ogivales) pour le culte en $1787^{8}$. Elle existe toujours, de même que la maison d'oraison au lieu-dit Chez Piet sur la commune de Lignières Sonneville ${ }^{9}$, vieille grange achetée à Jean Moindron en 1757, qui résista en 1759 au sac des dragons ${ }^{10}$.

Sur le grand nombre de maisons d'oraison qui devaient exister dans les Charentes, rares sont celles qui subsistent, comme celles de Villefagnan, Lignières Sonneville ou Arvert (fig. $\mathbf{n}^{\circ}$ 2). Elles constituent des lieux de la mémoire protestante essentiels de la région Poitou-Charentes ${ }^{11}$.

\section{Quelques caractéristiques des temples du XIX}

Selon Francette Joanne ${ }^{12}$, il ne faut attendre dans l'expression architecturale des temples ni luxe ni ornement. Les historiens protestants font peu de cas des études architecturales, car la théologie réformée accorde plus d'importance à l'écoute qu'au regard. Selon la loi et ses articles organiques, les temples doivent être construits à distance des églises, et situés hors du centre de la ville ou du bourg. On les retrouve donc le plus souvent à la périphérie, mais l'urbanisation du XIX ${ }^{\mathrm{e}}$ siècle aidant, les temples deviennent souvent des «têtes de pont » pour les nouveaux quartiers.

17 Le temple n'est pas orienté, ce n'est pas un lieu sacré, contrairement au croyant, dont Calvin dit qu'il est «le vrai temple de Dieu». Le temple devient lieu de culte lorsqu'il rassemble les fidèles. On trouve ainsi le plus souvent des temples de plan rectangulaire, avec un léger hémicycle à l'emplacement de la chaire et des tribunes placées soit au fond, soit sur plusieurs côtés. 
Figure 3

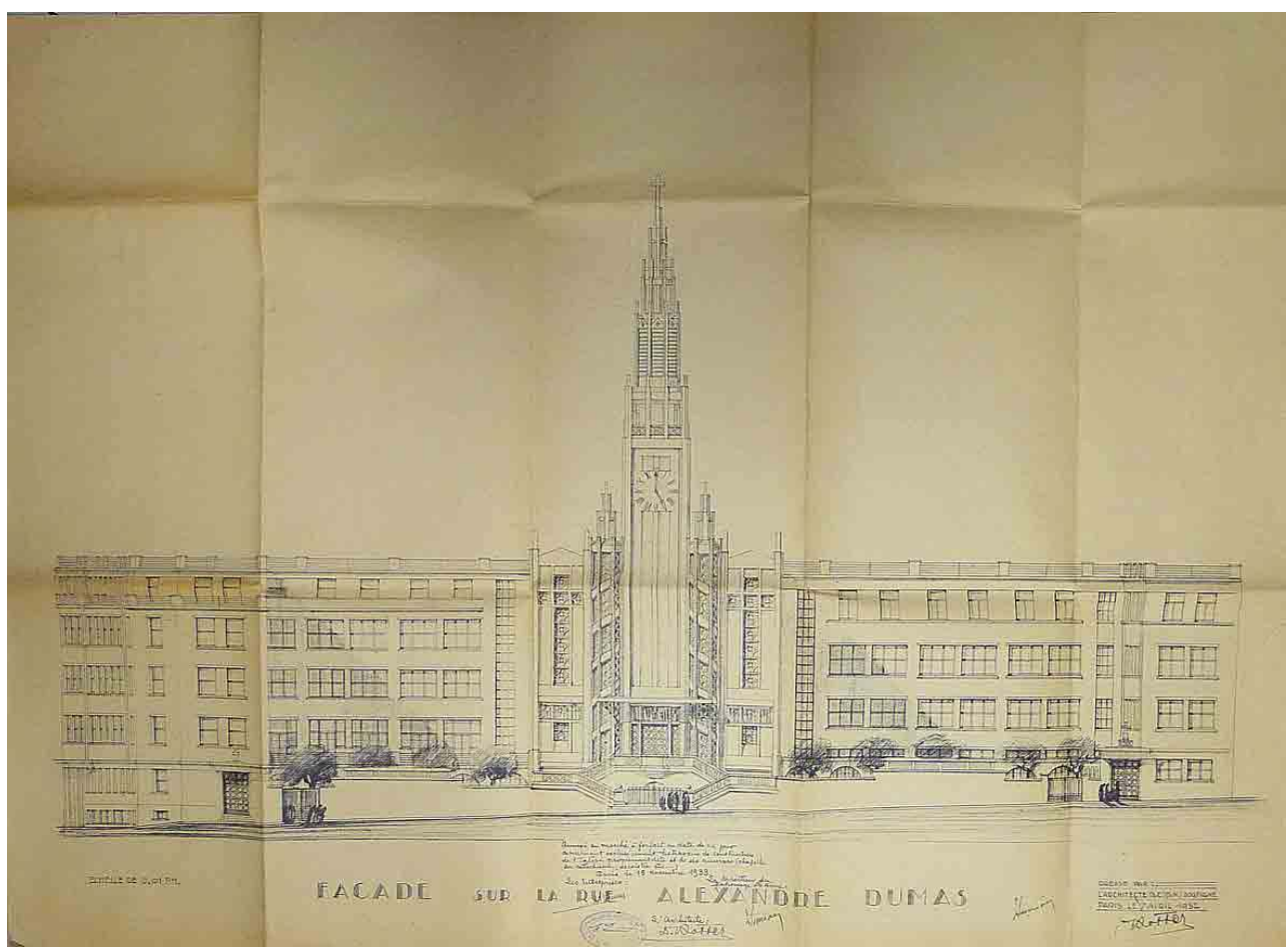

Saint-Sulpice-de-Royan (Charente-Maritime). Temple. Plan, extrait de Raguenet A. MonograPhIES DE BÂTIMENTS MODERNES. $100^{\circledR}$ numéro, vers 1900

(C) CRMH Poitou-Charentes, 2008

Deux temples sont de plan centré (octogonal à Saint-Sulpice-de-Royan, circulaire à SaintGelais) (fig. $\mathbf{n}^{\circ}$ 3). Le plan octogonal est extrêmement rare puisque seuls cinq autres sont connus dans toute la France (quatre dans les Cévennes et un à Mooréa à côté de Tahiti en Polynésie française, reconstruit en 1854). 


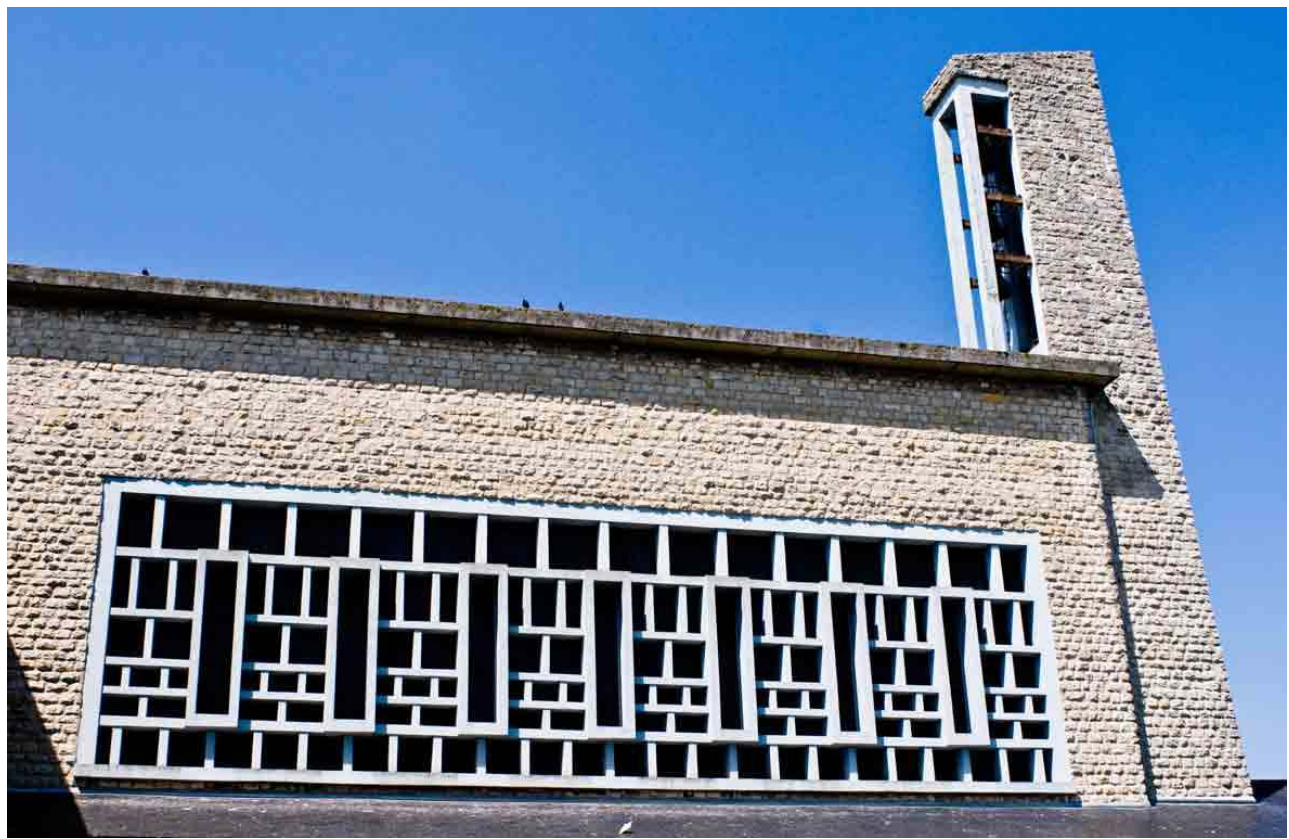

Segonzac (Charente). Temple. Vue intérieure

(c) CRMH Poitou-Charentes, 1998

Les fidèles se réunissent dans le temple pour écouter la parole de Dieu : la liturgie de la parole est essentielle dans le culte réformé. Le mobilier consiste en un ensemble de chaire, table de communion et bancs dont la disposition correspond aux exigences du culte. Au XIX siècle, c'est l'importance de la prédication qui détermine l'agencement. Un espace liturgique unique se trouve donc au devant de la chaire, monumentale avec son abat-voix : sa position, centrée sur le mur du fond, est mise en valeur par une allée axiale et une double (ou simple) volée d'escalier (fig. $\mathbf{n}^{\circ} \mathbf{4}$ ).

20 La table de communion et les bancs des anciens se tiennent comme à la source de la Vérité, au pied de la Parole. Les bancs des anciens existaient dans les temples antérieurs au XIX ${ }^{e}$ siècle : ils étaient disposés au pied de la chaire, sur un plancher légèrement surélevé. Les «anciens» étaient élus par le conseil presbytéral pour gérer la communauté. Cette caractéristique est très présente dans les temples charentais où l'estrade des bancs des anciens est séparée des autres bancs par une balustrade, ces anciens étant également des notables. 
Figure 5

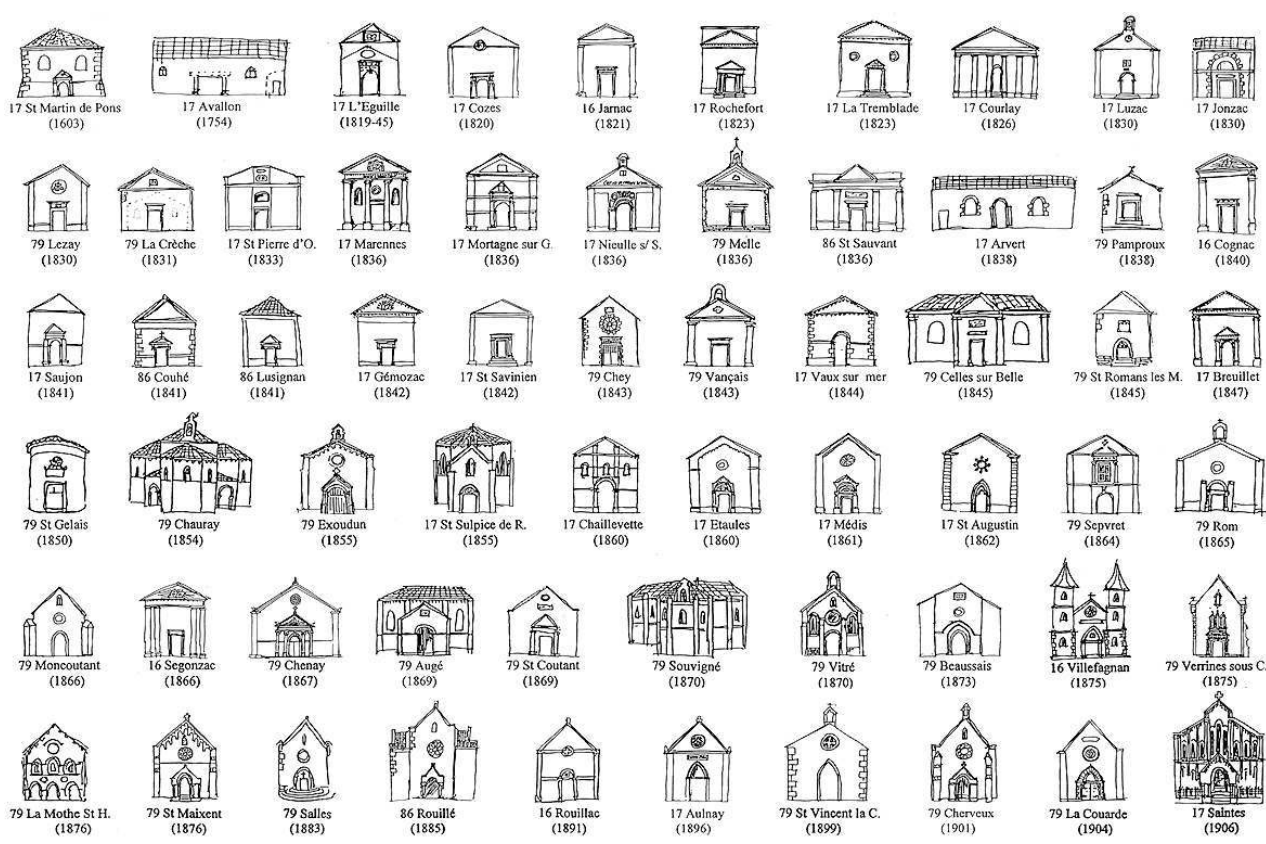

Croquis de 62 façades représentatives de temples, classées par ordre chronologique

(C) CRMH Poitou-Charentes, 1998

21 Le style néoclassique prédomine dans les façades (fig. $\mathbf{n}^{\circ}$ 5) jusqu'en 1840-1845. Style le plus courant à cette époque, il permet d'affirmer le caractère officiel du lieu, après plus de cent cinquante ans d'interdiction. Le style néomédiéval, voire romano-byzantin, est ensuite utilisé, à l'instar des églises catholiques.

\section{Sélection des temples protégés, approche et méthode}


Figure 6

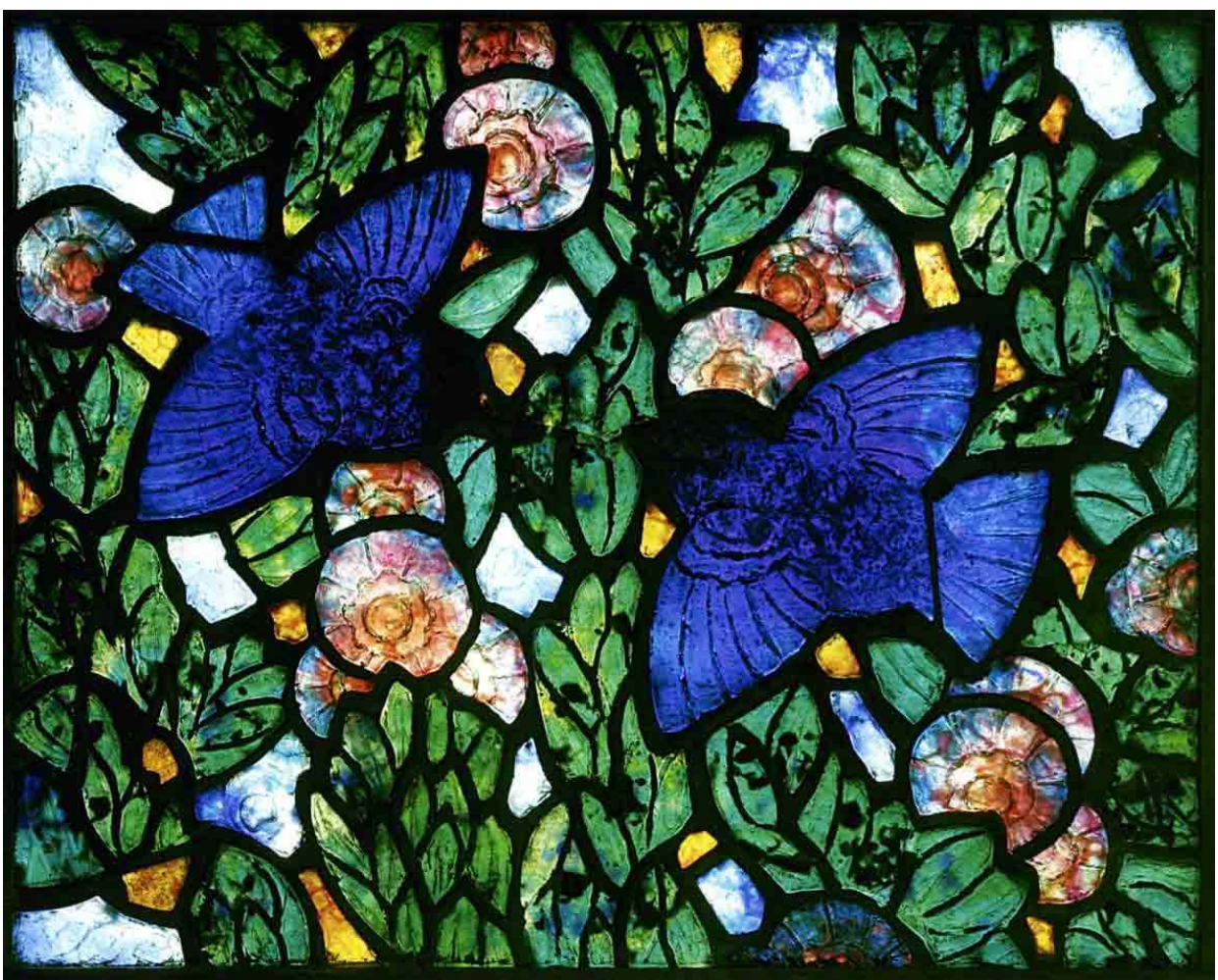

La Rochelle (Charente-Maritime). Temple (ancienne église des Récollets). Façade

(C) CRMH Poitou-Charentes, 1998

Un examen des listes du patrimoine protégé dans la région de Poitou-Charentes montre que le service des monuments historiques s'est peu intéressé à ce patrimoine. En effet, avant l'introduction de cette thématique, quatre temples étaient protégés au titre des monuments historiques en Poitou-Charentes, parmi lesquels on comptait trois anciennes églises réutilisées : le couvent des Récollets à La Rochelle ${ }^{13}$ (fig. $n^{\circ}$ 6), l'église de Beaussais ${ }^{14}$ dans les Deux-Sèvres ainsi que l'église de Cressac en Charente - affectée au culte protestant depuis 1904 - et un seul temple du XIX ${ }^{e}$ siècle, celui de Chauray (Deux-Sèvres). Un cimetière familial, le cimetière de la Chênaie à Breuillet (Charente-Maritime) était protégé au titre de la loi de 1930 sur les sites. 
Figure 7

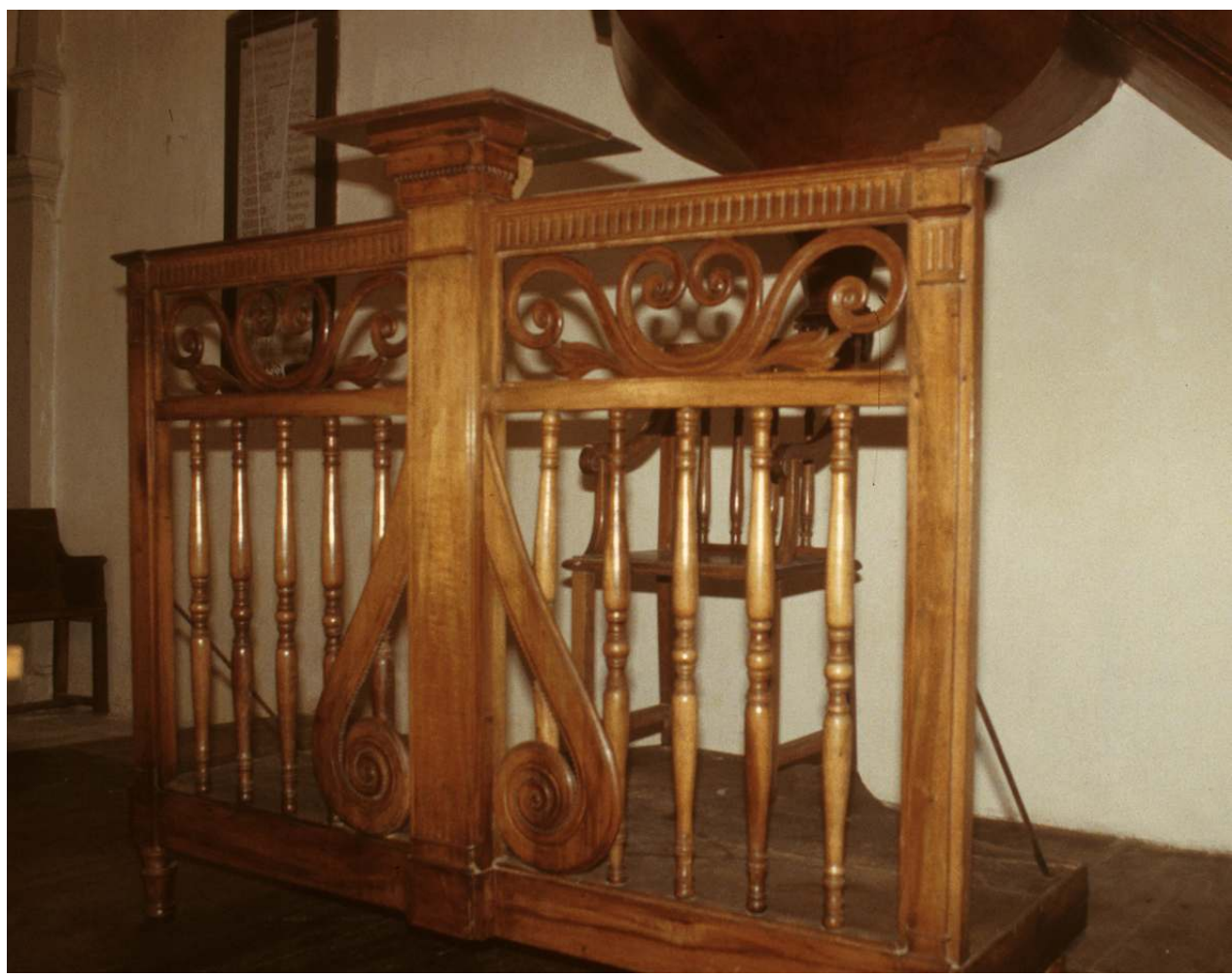

Cozes (Charente-Maritime). Temple. Pupitre de chantre

(c) CRMH Poitou-Charentes, 1998

Le patrimoine protestant se caractérisant en outre par la modestie et la rareté de son mobilier, seuls le pupitre de chantre de Cozes $^{15}$ (Charente-Maritime) inscrit le 7 juillet 1994) (fig. $n^{\circ} 7$ ) et une tapisserie des tables de la loi de Marsilly ${ }^{16}$ (Charente-Maritime) classée le 22 septembre 1994) sont protégés.

Par ailleurs, la restauration de quatre édifices a été financée au titre du patrimoine rural non protégé (P.R.N.P.) pour le temple de Saint-Sulpice-de-Royan en Charente-Maritime, les parties non protégées du temple de Beaussais, les temples de Verrines-sous-Celles et de Vançais dans les Deux-Sèvres.

$\mathrm{Au}$ niveau national, une enquête menée auprès des autres régions ${ }^{17}$ montre que le patrimoine protestant n'a pas fait l'objet d'une approche thématique. L'Alsace possède le plus grand nombre de temples protégés (35); il s'agit le plus souvent d'anciennes églises passées à la Réforme et adaptées au culte, avec quelques cas de simultaneum (chœur catholique et reste de l'édifice protestant).

Ainsi, l'expérience d'une approche globale tentée en Poitou-Charentes ne semble pas avoir été menée ailleurs. Elle a pu voir le jour grâce à diverses initiatives des protestants et de l'association Poitou-Saintonge-Protestants ainsi que grâce au travail d'enquête mené par le service. Plusieurs rencontres et les réunions d'un groupe de travail ont permis d'aboutir à une sélection des temples les plus représentatifs sur les 130 que compte la région : 58 en Charente-Maritime, 40 en Deux-Sèvres, 24 en Charente et 8 dans la Vienne. 


\section{Critères du choix des 17 temples retenus}

\section{a) Critères architecturaux}

- qualité architecturale, caractère remarquable : Saintes, Cozes (Charente-Maritime), Rouillé (Vienne), façade du temple de Chenay, Verrines-sous-Celles ${ }^{18}$ (Deux-Sèvres) ;

- caractère unique du plan ou originalité de la construction: Villefagnan (Charente), SaintGelais, Souvigné (Deux-Sèvres), Saint Sulpice de Royan (Charente-Maritime) ;

- représentativité par rapport à une typologie fréquemment employée: Vançais (DeuxSèvres), Jarnac, Segonzac (Charente) (style néoclassique).

\section{b) Critères historiques}

- ancienneté : murs du XVII ${ }^{\mathrm{e}}$ siècle à Pons, du XVIII ${ }^{\mathrm{e}}$ siècle à Jarnac ; premières constructions du XIX ${ }^{e}$ siècle à l'Éguille et Cozes. A contrario, La Couarde ${ }^{19}$ (Deux-Sèvres) et Saintes ont été les derniers temples construits avant la loi de séparation de l'Église et de l'État.

- prégnance du passé huguenot: Segonzac, Pons (Charente-Maritime), Exoudun ${ }^{20}$ (DeuxSèvres), Jarnac, Villefagnan.

\section{c) L'affectation au culte}

L'usage religieux des édifices a été défini comme une priorité. Àl'exception de celui de La Couarde - devenu «maison du protestantisme » et celui de Pons - désaffecté pour cause de mauvais état - tous les temples servent, à l'occasion ou en permanence, pour les cérémonies religieuses. N.B. : à Chenay, le temple, transformé en salle polyvalente, est toujours utilisé pour le culte protestant si nécessaire.

\section{d) L'intégration dans le site urbain}

Ce critère concerne surtout le temple de Vançais qui se trouve face à l'église sur la place du village.

Le temple d'Exoudun, archétype du village protestant, est tout aussi emblématique, à l'instar du temple de Souvigné aussi important en taille et en monumentalité que l'église située plus loin dans le village.

\section{e) La présence de mobilier}

30 Le temple de Cozes abrite les seuls objets protégés. De la même façon, la majorité des temples a conservé le mobilier modeste mais d'origine (bancs, chaire et tribune) : Saintes, Saint-Sulpice de Royan, Jarnac, Segonzac, Souvigné, etc.

\section{f) Lieux de mémoire}

31 Ce critère s'applique à tous les temples, tant l'histoire de leur construction/ reconstruction est liée à une histoire nationale et locale, qui a tissé des liens sociaux et affectifs encore tangibles jusque dans les comportements actuels.

Cependant, les temples de Souvigné et de La Couarde (maison du protestantisme) (DeuxSèvres), devenus les sièges de manifestations culturelles autour du protestantisme, étaient plus particulièrement désignés. 
33 Liste des temples sélectionnés et mesures de protection retenues après avis de la commission régionale du patrimoine historique, archéologique et ethnologique du 27 mai 1998 :

$\mathrm{IMH}=$ inscription au titre des monuments historiques, suivi de la date de signature de l'arrêté de protection par le préfet de région.

Charente :

- Jarnac, temple : IMH 26.10.1998

- Segonzac, temple : IMH 29.09.1998

- Villefagnan, temple : IMH 26.10.1998

\section{Charente-Maritime :}

- Cozes, temple : IMH 21.09.1998

- L'Éguille, temple : refus de protection

- Pons, église Saint-Martin (ancien temple) : IMH 26.10.1998

- Pons, temple (ancienne chapelle des Dames de la Foi) : refus de protection

- Saint-Sulpice-de-Royan, temple IMH 23.09.1998

- Saintes, temple : IMH 26.10.1998

\section{Deux-Sèvres :}

- Chenay, temple : façade IMH 21.09.1998

- La Couarde, temple : refus de protection

- Exoudun, temple : refus de protection

- Saint-Gelais, temple : IMH 21.09.1998

- Souvigné, temple : IMH 21.09.1998

- Vançais, temple : IMH 21.09.1998

- Verrines-sous-Celles, temple : refus de protection

Vienne :

- Rouillé, temple : IMH 21.09.1998 


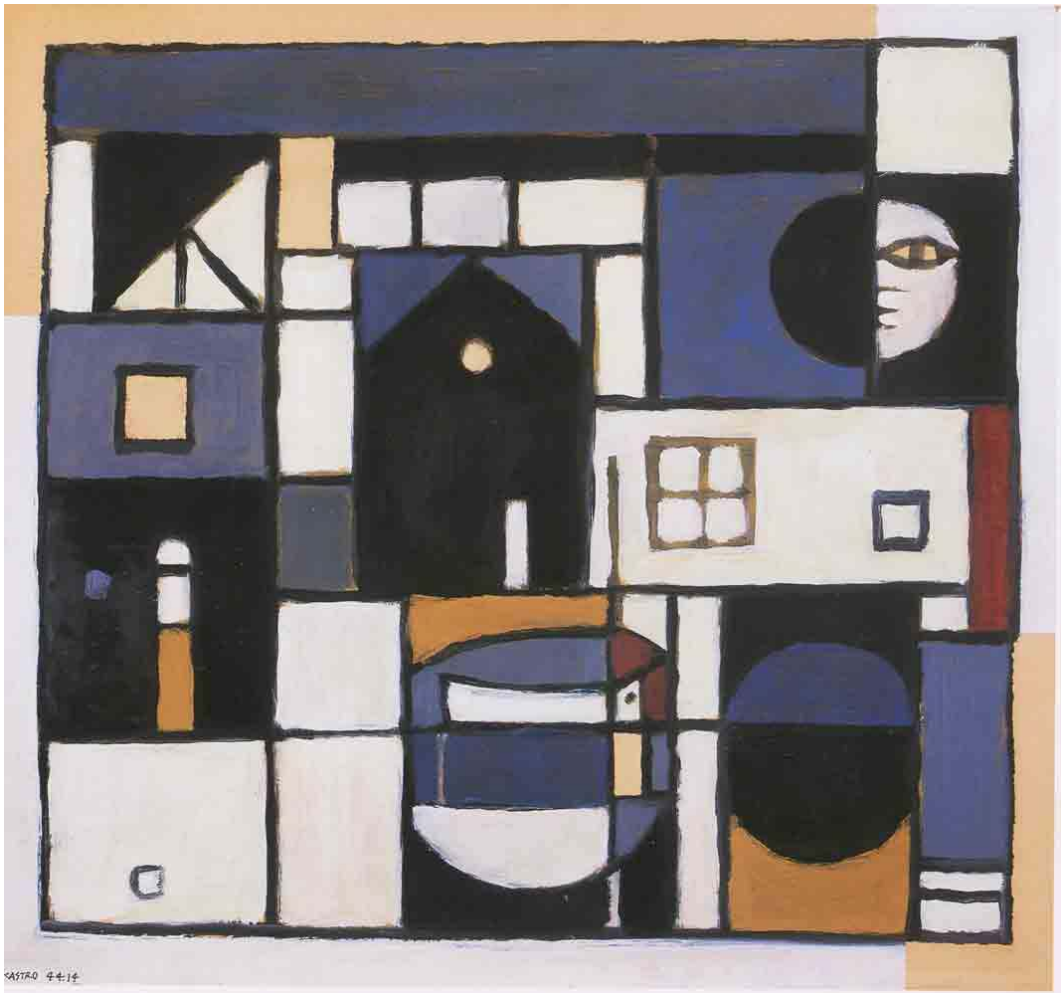

Carte de l'implantation des temples protestants en Poitou-Charentes, d'après MOURS, Samuel. LES ÉgLISES RÉFoRMÉES EN FRANCE. Paris : Librairie protestante, 1958

(C) CRMH Poitou-Charentes, 2008

Au total, sur les 17 temples présentés, 12 temples ont été inscrits au titre des monuments historiques (en plus de celui de Chauray inscrit depuis le 7 mars 1988), comme autant d'illustrations des traces de l'histoire du protestantisme de la région Poitou-Charentes (fig. $\left.\mathbf{n}^{\circ} \mathbf{8}\right)$.

À cette liste se rajoute le centre protestant de Royan (Charente-Maritime), dont le temple, le parvis, la salle des fêtes, le logement du gardien et le presbytère ont été inscrits au titre des monuments historiques par arrêté du 4 septembre 2002 dans le cadre de la thématique « Patrimoine $\mathrm{XX}^{\mathrm{e}}$ ».

\section{Notices des temples protégés au titre des monuments historiques $^{21}$}

Temple de Jarnac (Charente) ${ }^{22}$. Propriété privée 


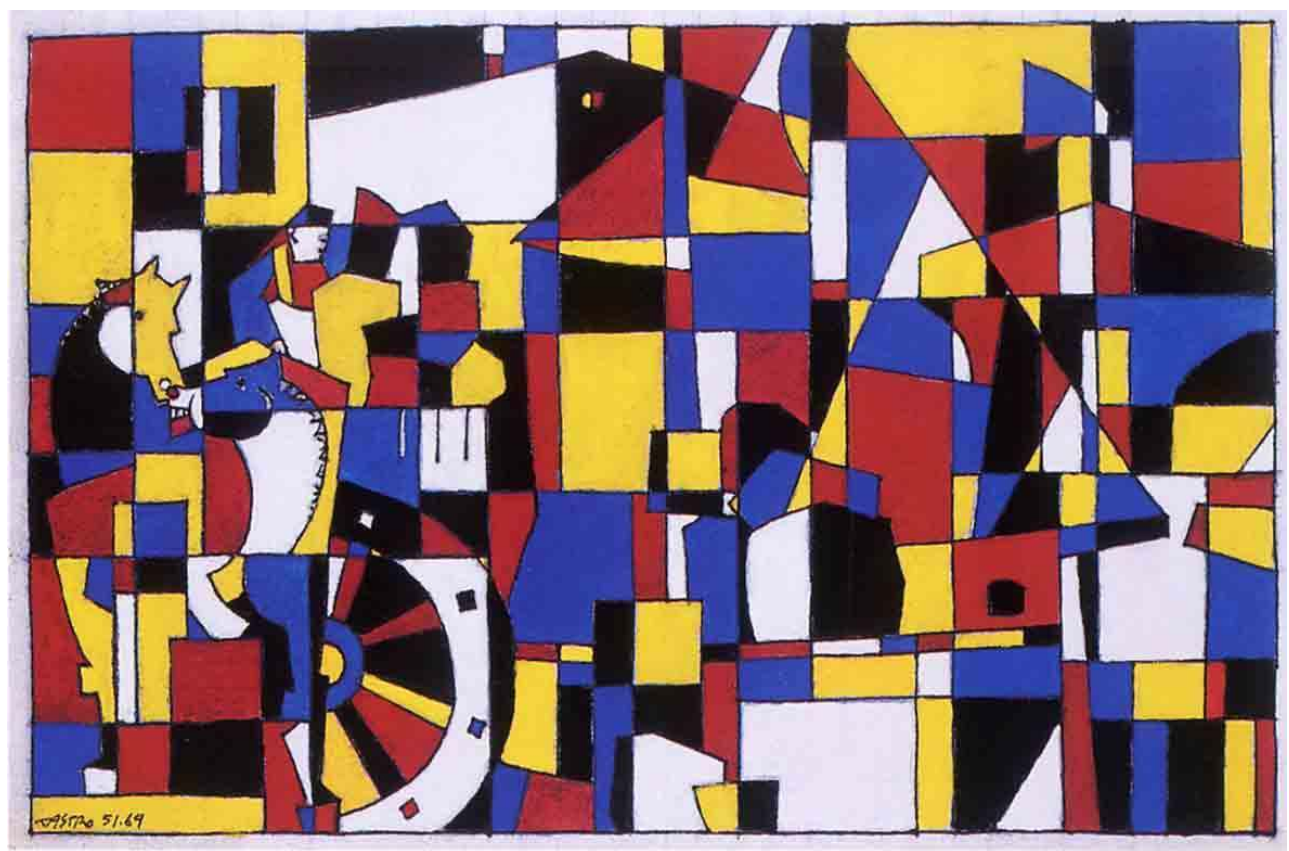

Jarnac (Charente). Temple. Plan, coupe et élévation, 1821, A.N.F 21

(c) CRMH Poitou-Charentes, 1998

41 Jarnac est, avec Cognac, Segonzac et Châteauneuf, un des foyers calvinistes de l'Angoumois. Un colloque s'y est réuni dès 1560. Jarnac est aussi, le 13 mars 1569, le théâtre d'un combat décisif et mémorable entre l'armée catholique, dirigée par le duc d'Anjou, et l'armée protestante menée par le prince de Condé, qui y trouve la mort.

Le temple actuel, de plan rectangulaire très allongé - environ $30 \mathrm{~m}$ de long par 10 de large - (fig. $n^{\circ} 9$ ), est constitué de deux parties distinctes : la première, qui sert de lieu de culte et de sacristie, est en fait la maison d'oraison construite en 1761, ancienne grange de Jean Ranson de Bois-Blanchard, rehaussée et percée de fenêtres en demi-cercle au XIX ${ }^{\mathrm{e}}$ siècle ; la seconde partie correspond à l'extension construite après 1820 par Paul Abadie père (1783-1868), sur les plans de François Nicolas Pineau (1746-1823), possédant une façade sur rue néo-classique, sobre et équilibrée, à usage actuel d'accueil (fig. $\mathrm{n}^{\circ} 10$ ). Cette façade est une des premières constructions protestantes du XIX ${ }^{\mathrm{e}}$ siècle en Poitou-Charentes. L'aménagement intérieur, (fig. $n^{\circ} 11$ ) sacristie, tribune, baies en demi-cercle ornées de vitraux aux motifs de feuilles d'acanthe, est dû à l'architecte Albert Cochot à la fin du XIX ${ }^{\mathrm{e}}$ siècle (1888), qui remplace la charpente et reconstruit le plafond. 
Figure 10

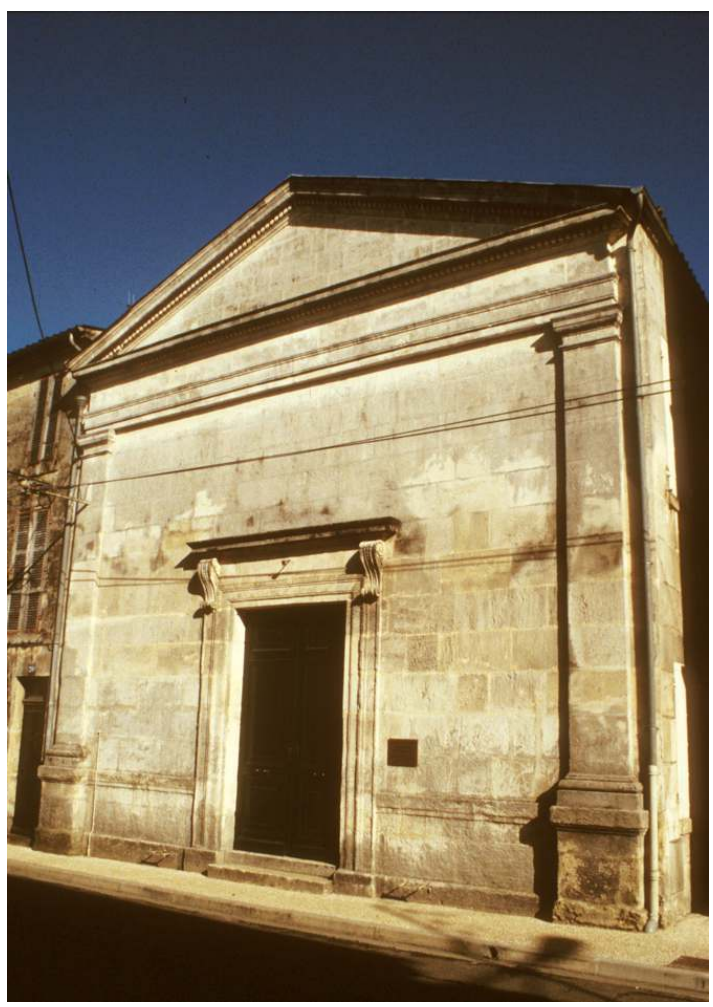

Jarnac (Charente). Temple. Façade

(C) CRMH Poitou-Charentes, 1998

\section{Figure 11}

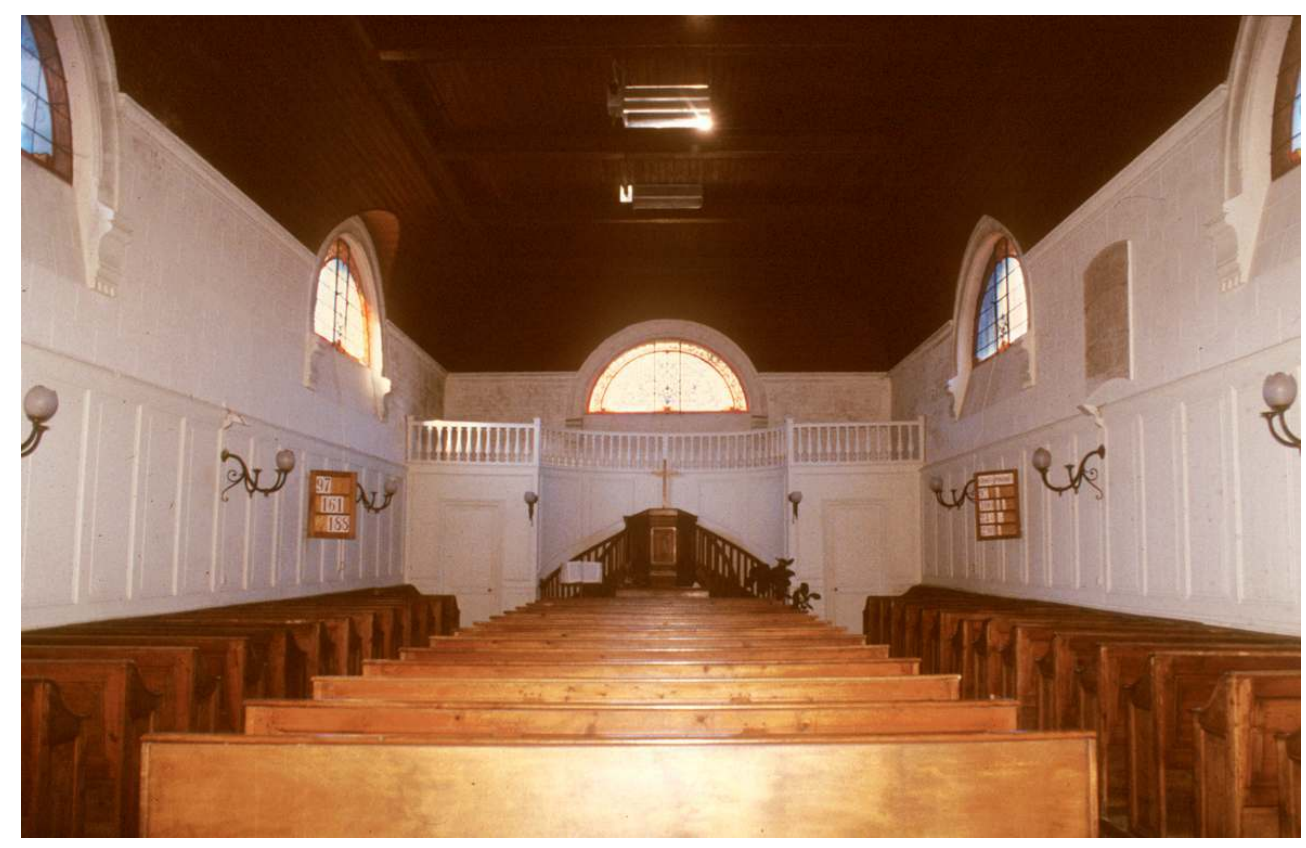

Jarnac (Charente). Temple. Vue intérieure

(c) CRMH Poitou-Charentes, 1998 


\section{Temple de Segonzac (Charente) ${ }^{23}$. Propriété communale}

Figure 12

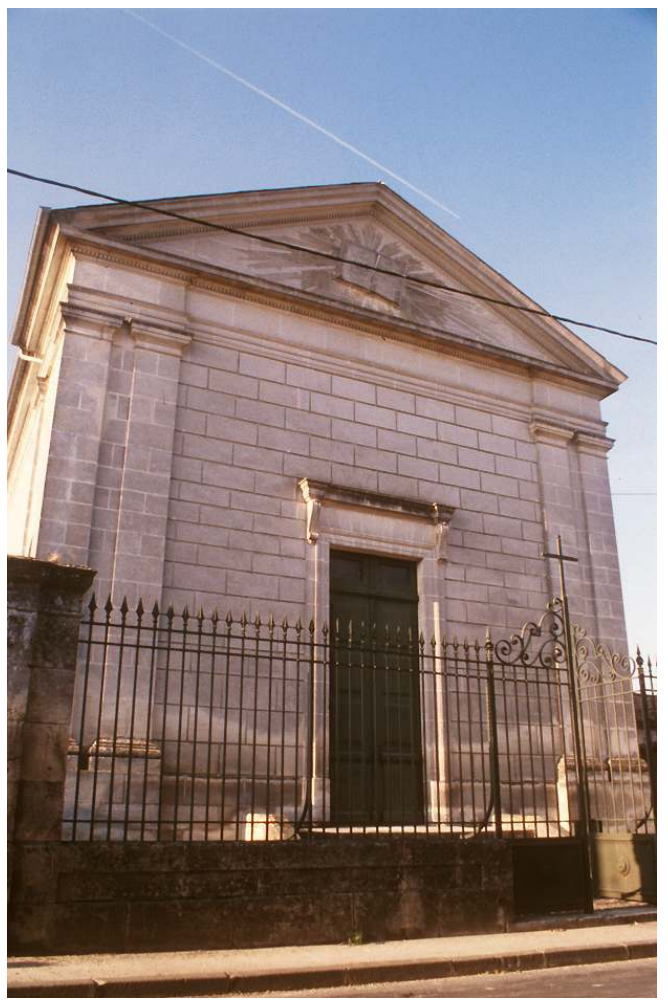

Segonzac (Charente). Temple. Façade

(c) CRMH Poitou-Charentes, 1998

43 Ce temple est un témoin essentiel de l'histoire protestante en Charente : Segonzac adhère massivement à la Réforme, voit se fonder en 1558 une des premières églises en Angoumois et constitue à travers le temps un noyau fidèle au culte réformé. Elle est notamment l'un des lieux principaux d'assemblées clandestines de la région après la révocation de l'édit de Nantes. L'édifice actuel, troisième temple édifié sur la commune, est construit entre 1864 et 1869, sur des plans de l'architecte Alphonse Demenieux (activité connue de 1855 à 1866), qui s'inspire certainement du temple de Cognac $^{24}$ construit en 1838-1840 sous la direction de Paul Abadie (1812-1884) - à qui il ressemble comme un frère.

44 Le temple de Segonzac est le plus grand de Charente. Ses dimensions imposantes - $25 \mathrm{~m}$ de long par $12 \mathrm{~m}$ de large -, accentuées par sa situation isolée, lui confèrent une monumentalité indéniable. Parfaitement représentatif de la typologie particulière des temples néo-classiques édifiés au XIX ${ }^{\mathrm{e}}$ siècle, il possède une construction en pierre de taille extrêmement soignée, ainsi qu'un mobilier très intéressant. Il a conservé l'intégralité de son décor et de son mobilier d'origine, dus au même architecte : boiseries, stalles, chaire, bancs, ainsi qu'une remarquable table de communion (fig. $n^{\circ} 12$ ). 


\section{Temple de Villefagnan (Charente) ${ }^{25}$. Propriété privée} tôt les idées de la Réforme. Grâce à sa situation sur la grande route du Sud-Ouest, elle devient rapidement un centre de rayonnement qui lui valut autrefois d'être appelée la Petite Genève. Le temple actuel, le cinquième édifié sur la commune, est l'œuvre du pasteur Picanon, qui exerce son ministère à Villefagnan de 1864 jusqu'à sa mort en 1898. Homme d'une prodigieuse activité, il parvient à faire renaitre la foi dans cette campagne longtemps abandonnée et, grâce à des collectes et des appels, à réunir les fonds nécessaires à la construction d'un nouveau temple, inauguré le 27 octobre 1875.

L'édifice est de plan rectangulaire, flanqué en façade de deux tours-clochers carrées débordantes et terminé d'une abside pentagonale. Ramassé de par ses dimensions ( $15 \mathrm{~m}$ de long, $7 \mathrm{~m} 30$ de large pour la nef et son abside et $10 \mathrm{~m}$ de large sur $3 \mathrm{~m} 50$ de profondeur pour la façade), le bâtiment offre cependant une silhouette élancée grâce à ses deux tours, qui en firent sa renommée : elles lui confèrent une typologie proche de celle d'une église catholique et originale à ce titre (fig. $\left.n^{\circ} 13, n^{\circ} 14\right)$.

Figure 13

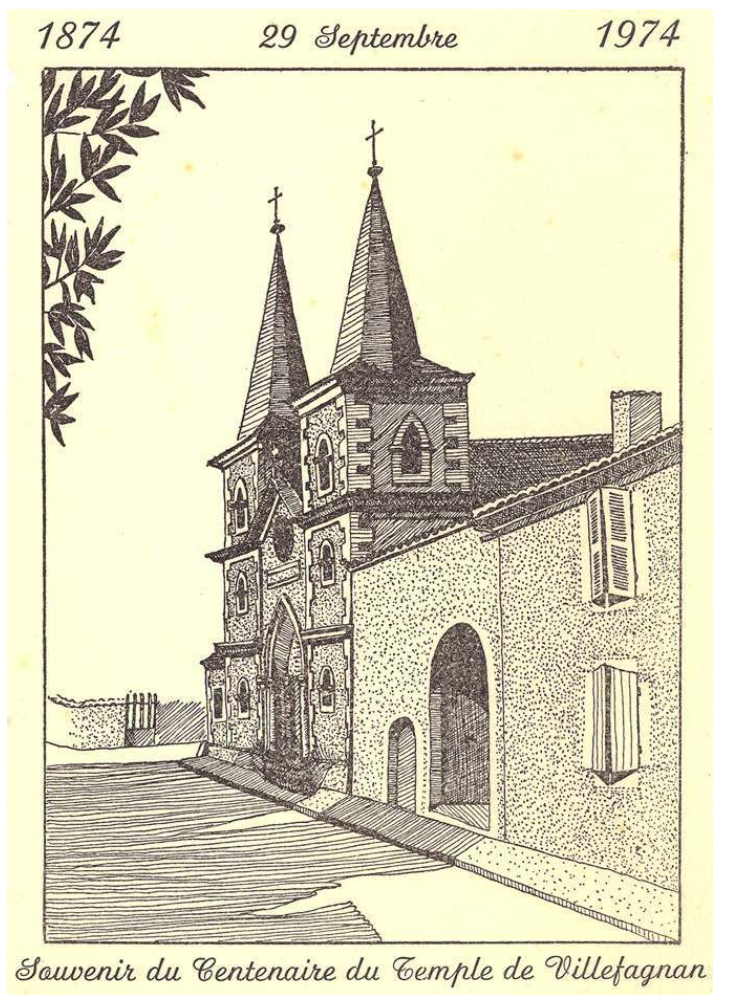

Villefagnan (Charente). Temple. Carte souvenir du centenaire du temple le 29 septembre 1974, signée par Jean Rivierre

(c) CRMH Poitou-Charentes, 1998 


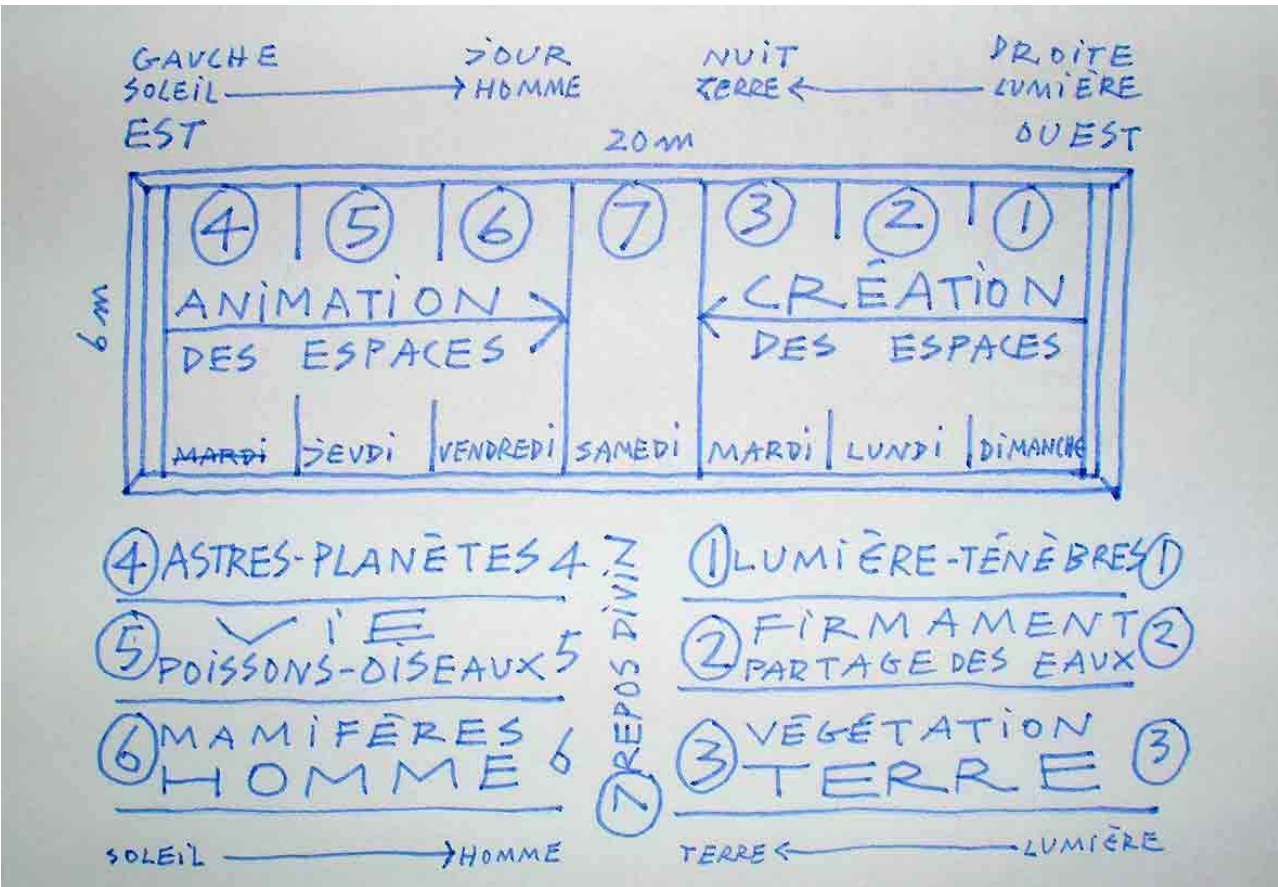

Villefagnan (Charente). Temple. Vue intérieure

(c) CRMH Poitou-Charentes, 1998

\section{Temple de Cozes (Charente-Maritime) ${ }^{26}$. Propriété communale}




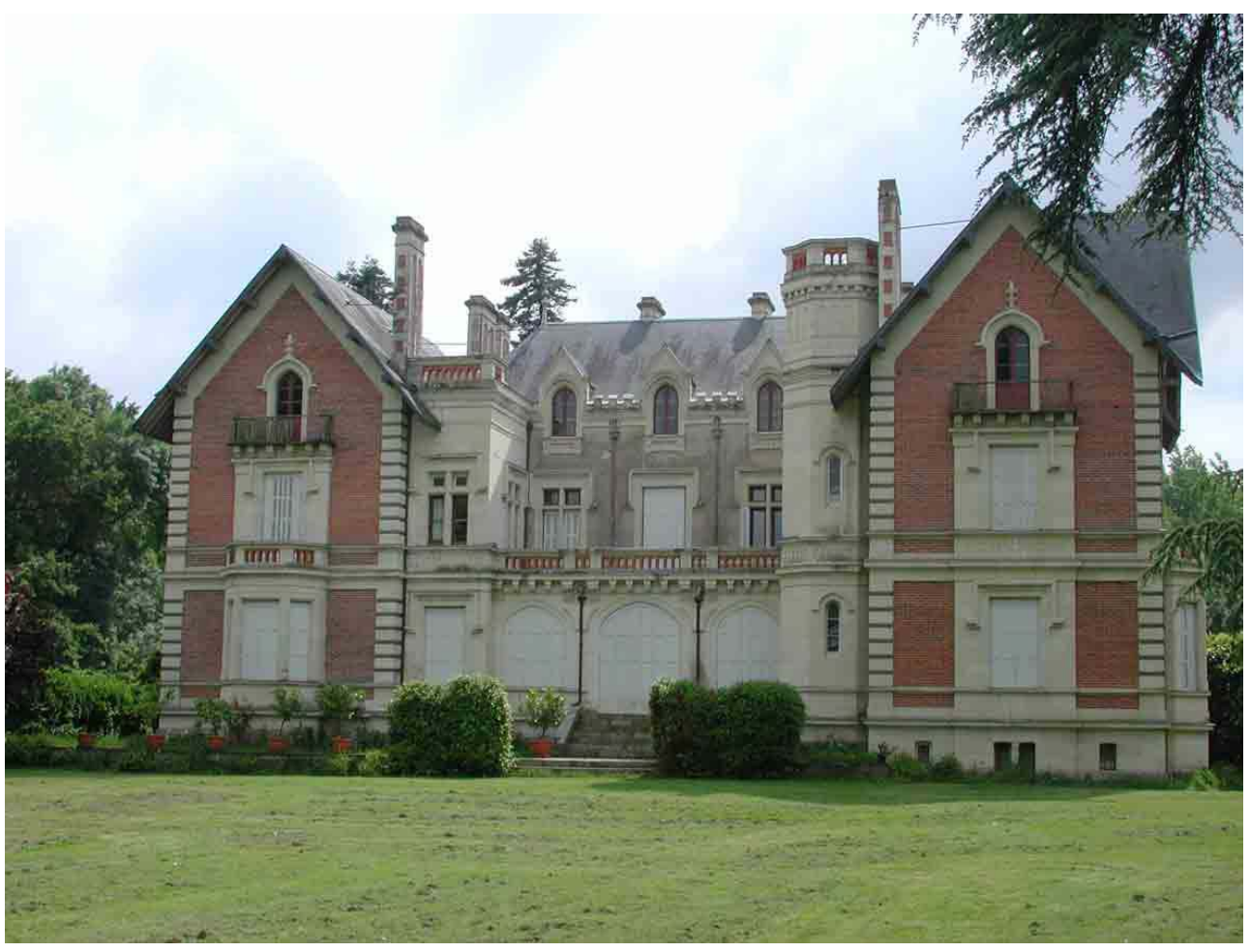

Cozes (Charente-Maritime). Temple. Plan

(c) CRMH Poitou-Charentes, 1998

$47 \mathrm{Au} \mathrm{XVII}$ siècle, la communauté protestante est très active à Cozes et un temple existe dans le bourg jusqu'à la révocation de l'édit de Nantes. Un second temple est construit au XVIII ${ }^{e}$ siècle à la Font-Rolland. Le temple actuel date de 1817-1821. C'est un édifice rectangulaire de $17,5 \mathrm{~m}$ de long et $14 \mathrm{~m}$ de large (fig. $\mathrm{n}^{\circ} 15$ ), aux murs de moellons enduits, à chaînes d'angle harpées et corniche moulurée. Les fenêtres cintrées sont sans ornement et seule la façade sur rue possède un décor architectural : fronton à oculus, porte à pilastres doriques et entablement sculpté. L'intérieur est une vaste salle au sol pavé de terre cuite, bordée sur trois côtés par une colonnade à deux niveaux qui donne un effet monumental et augmente la capacité du temple (415 places) au moyen de grandes tribunes (fig. $\mathrm{n}^{\circ} 16$ ). Les supports sont des colonnes en bois massif, à chapiteaux en stuc, toscans au premier niveau et ioniques au second (fig. $n^{\circ} 17$ ). Ce temple est l'un des plus anciens de Poitou-Charentes et il se distingue par son aménagement intérieur, ambitieux pour l'époque. Il a gardé tout son mobilier liturgique du début du XIX siècle, dont un beau pupitre de chantre à balustrade, inscrit au titre des objets mobiliers le 7 juillet $1994^{27}$ 
Figure 16

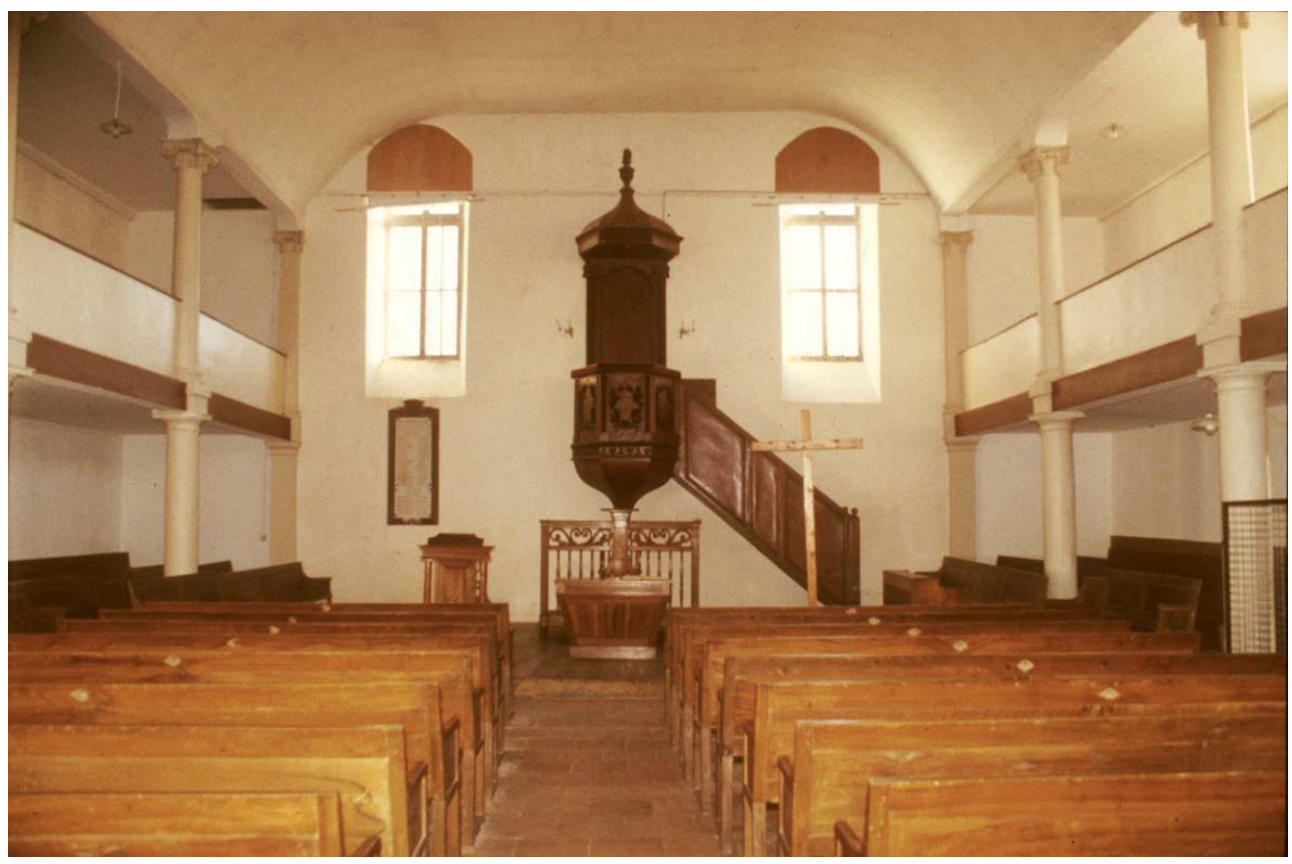

Cozes (Charente-Maritime). Temple. Vue intérieure

(c) CRMH Poitou-Charentes, 1998

\section{Figure 17}

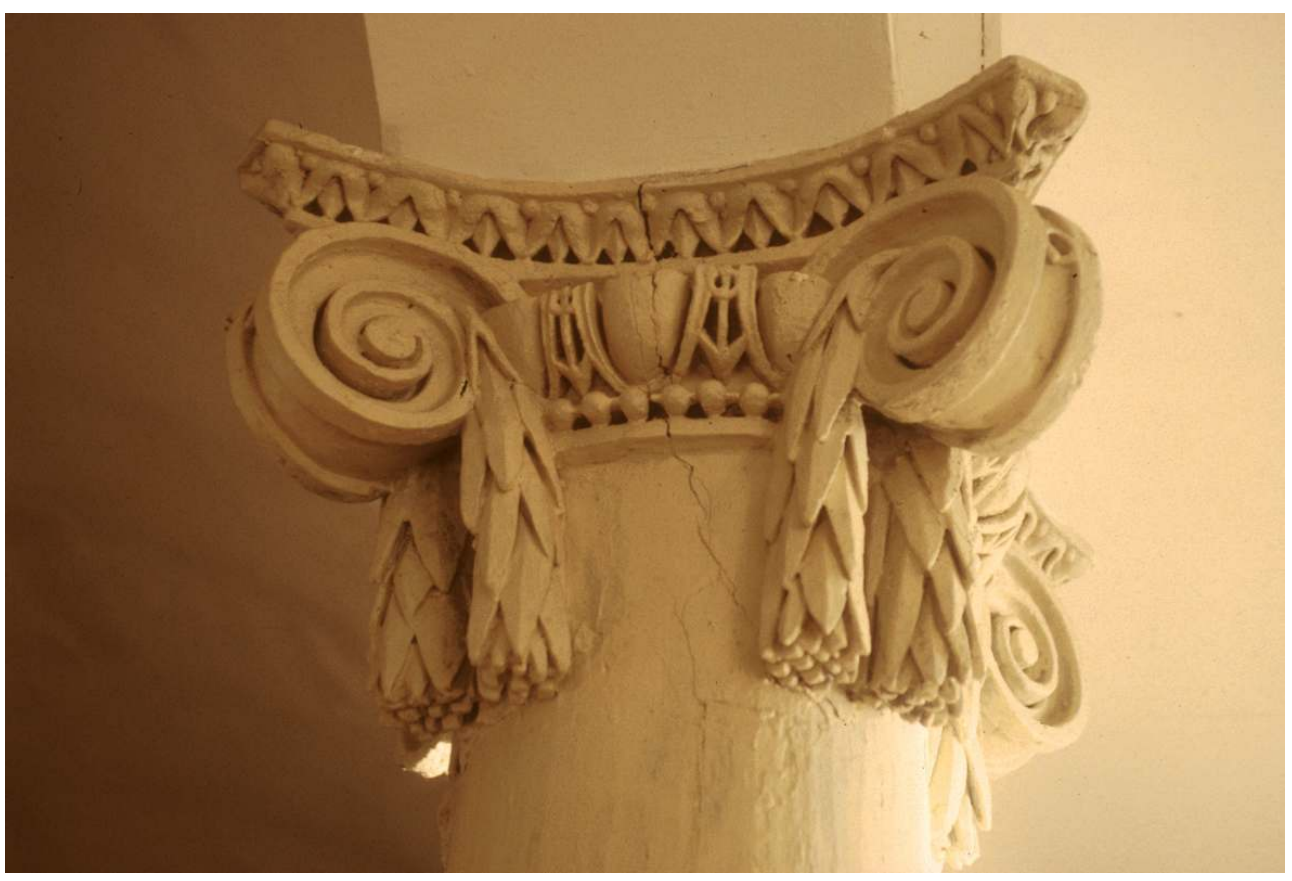

Cozes (Charente-Maritime). Temple. Détail d'un chapiteau

(c) CRMH Poitou-Charentes, 1998 


\section{Ancien temple de Pons, actuellement église Saint-Martin (Charente- Maritime) ${ }^{28}$. Propriété communale}

Figure 18

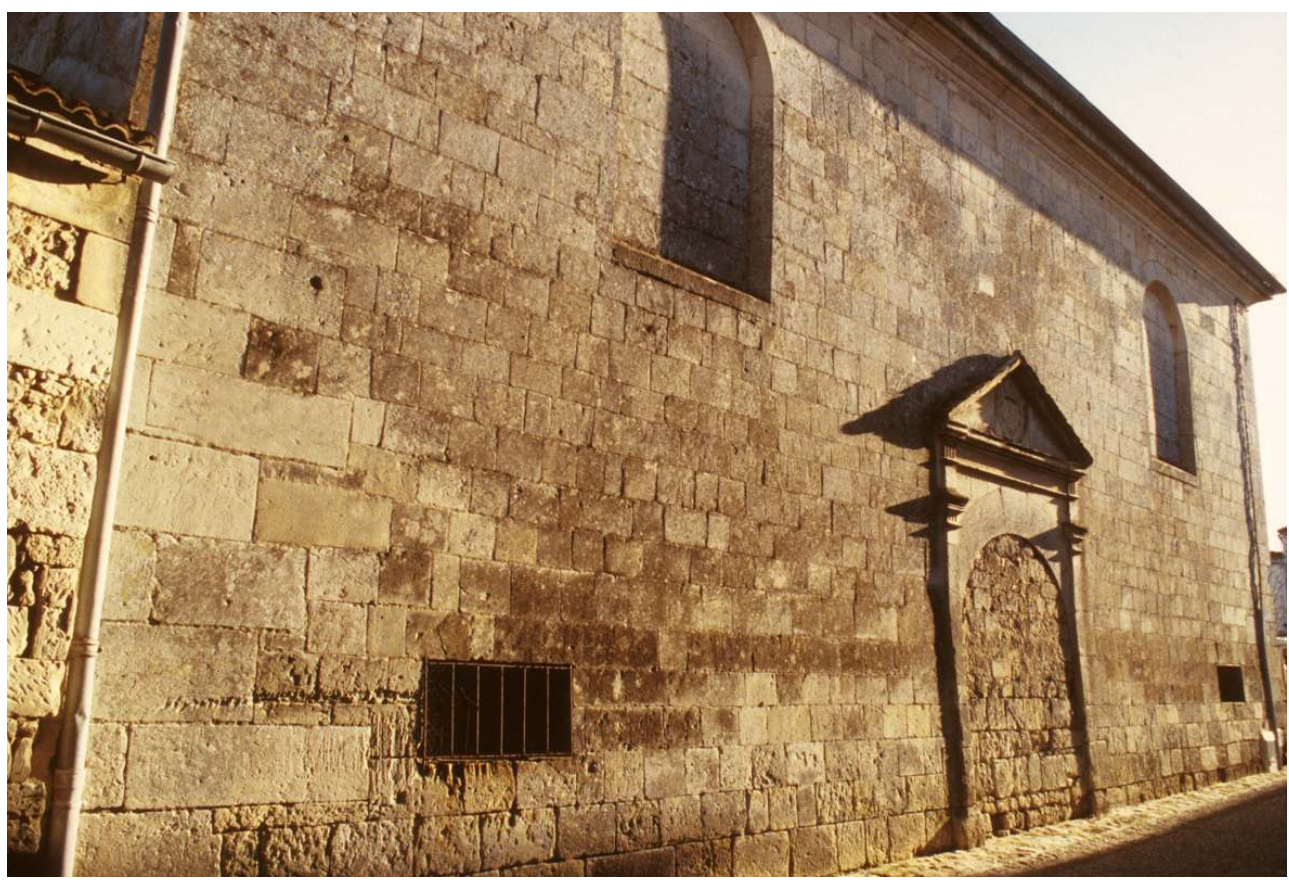

Pons (Charente-Maritime). Temple. Élévation extérieure

(c) CRMH Poitou-Charentes, 1998

Le premier temple de Pons fut construit au XVI ${ }^{e}$ siècle à l'emplacement de l'église SaintSauveur. Il se révèle vite trop petit et un édifice plus vaste le remplace vers 1603. En 1629, ce temple est confisqué et devient la chapelle des Récollets, avant d'être érigé en église paroissiale Saint-Martin. Vers 1829-1833, l'édifice est agrandi et doté d'un clocher, ce qui lui donne sa physionomie actuelle. Son plan est un rectangle de $16,5 \mathrm{~m}$ de long sur $40,5 \mathrm{~m}$ de large, doté d'un transept bas. Les murs extérieurs d'une grande moitié ouest sont du début du XVII e siècle : moyen appareil presque cubique, soubassement en talus, vestiges de baies en lancettes et portes murées à décor classique, dont une est munie des armes bûchées d'Henri de Navarre. Le reste des élévations est entièrement du XIX ${ }^{e}$ siècle : façades à décor monumental, clocher à dôme en pierre. L'aménagement intérieur, également $\mathrm{du} \mathrm{XIX}^{\mathrm{e}}$ siècle, reprend peut-être le schéma d'origine: files de piliers délimitant un vaisseau central couvert d'un grand berceau surbaissé, et deux bas-côtés à berceaux transversaux.

L'église Saint-Martin présente un intérêt indéniable pour l'histoire du protestantisme car toute sa partie ouest constitue le seul vestige architectural d'envergure connu dans la région d'un temple protestant construit entre l'édit de Nantes et sa révocation (fig. $n^{\circ} 18$ ).

\section{Temple de Royan (Charente-Maritime) ${ }^{29}$. Propriété communale et privée}


Figure 19

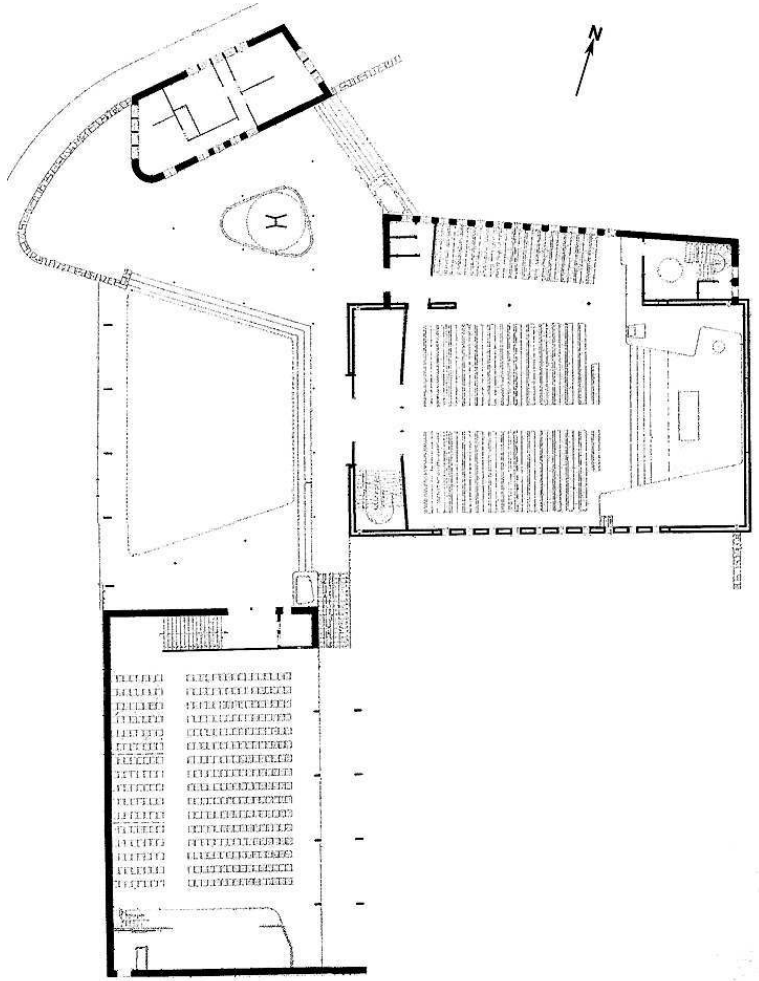

Royan (Charente-Maritime). Temple. Plan déposé en mairie en août 1953 par l'agence Baraton, Bauhain et Hébrard

(c) CRMH Poitou-Charentes, 2001

Des trois architectes qui constituent l'agence créée en 1946 à Pontaillac par René Baraton, Jean Bauhain et Marc Hébrard, il semble que l'on doive le temple de Royan au seul Marc Hébrard (1909-1979). Ce dernier obtient son diplôme en 1932, travaille au service de l'architecture de la préfecture de Clermont-Ferrand, puis à Paris dans le cabinet d'Auguste Perret (1874-1954) avant de rejoindre Royan. De religion protestante, il se charge seul du projet du temple. A. Bourbonnais (1925-1988), architecte, et J. Morel, ingénieur, l'assistent dans les études. Après avoir élaboré deux projets, le programme s'arrête sur la construction d'un centre protestant comprenant un temple, deux salles de réunion dont une est placée sous le temple tirant parti de la déclivité du terrain (fig. $\mathrm{n}$ -19). Un peu à l'écart se trouve la maison du pasteur. La construction de tels centres multi-fonctionnels, foyers spirituels ou relais cultuels, plus adaptés à la vie des cités, est assez fréquente après la Seconde Guerre mondiale tant chez les catholiques que chez les protestants. 
Figure 20

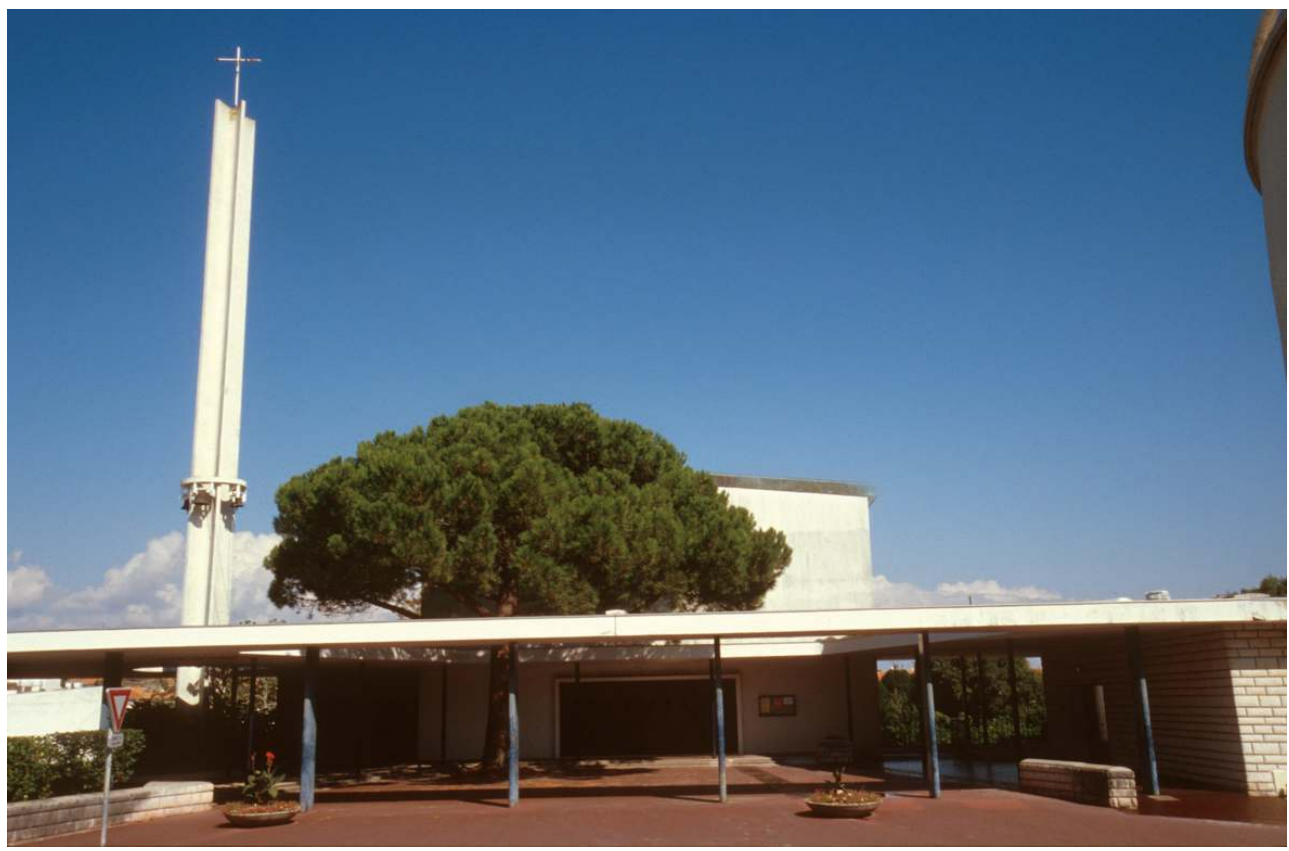

Royan (Charente-Maritime). Temple. Vue extérieure

(c) CRMH Poitou-Charentes, 2001

51 Le temple se présente sous la forme d'une simple salle trapézoïdale couverte d'un toit à double pente. La façade principale en est la coupe fidèle et dénuée de tout décor. Le parvis qui précède le temple est traité comme un vaste espace ouvert, ceint d'une galerie, qui repose sur des voiles de métal bleu en méplat, selon un modèle que l'on retrouve souvent à Royan (fig. $\left.n^{\circ} 20\right)$. Sur le côté nord du parvis, le toit-terrasse de la galerie est percé d'une trémie ovoïde, à travers laquelle s'élance un fin clocher en béton en forme de $\mathrm{H}$, à 4 cloches et haut de $18 \mathrm{~m}$. Cet espace intermédiaire, à ciel ouvert, que module en permanence le jeu de l'ombre et de la lumière, évoque à certains fidèles protestants le culte du désert. En 1962 a été installé dans le temple un orgue de Schwenkedel.

\section{Temple de Saint-Sulpice-de-Royan (Charente-Maritime) ${ }^{30}$. Propriété communale}

52 Aux $\mathrm{XVII}^{\mathrm{e}}$ et $\mathrm{XVIII}^{\mathrm{e}}$ siècles, les réformés de Saint-Sulpice fréquentent successivement plusieurs temples des alentours (Saujon, le « Pouyaud», les « Maries »). Devant le nombre croissant de protestants, la construction d'un temple dans le bourg même est entreprise en 1818. Devenu trop exigu, ce bâtiment est remplacé par le temple actuel en 1854-55, selon le projet de Léon Jossier, architecte parisien (1825-1862). Il s'agit d'un octogone de 6 $\mathrm{m}$ de côté, soigneusement construit en pierre de taille et moellons, et étayé par des contreforts-pilastres angulaires (fig. $\mathbf{n}^{\circ} \mathbf{2 1}$ ). Il reçoit un éclairage abondant par des triplets de baies élancées en plein cintre. L'entrée s'effectue par un vestibule rectangulaire à pignon, surmonté d'un clocher-mur. À l'intérieur, chaque mur est orné d'une grande arcade plein cintre, le sol est en tommettes et le couvrement est une majestueuse charpente à huit demi-fermes rayonnantes. Une vaste tribune à avancées en menuiserie peinte en faux bois permet d'atteindre une capacité de 450 places. 
Figure 21

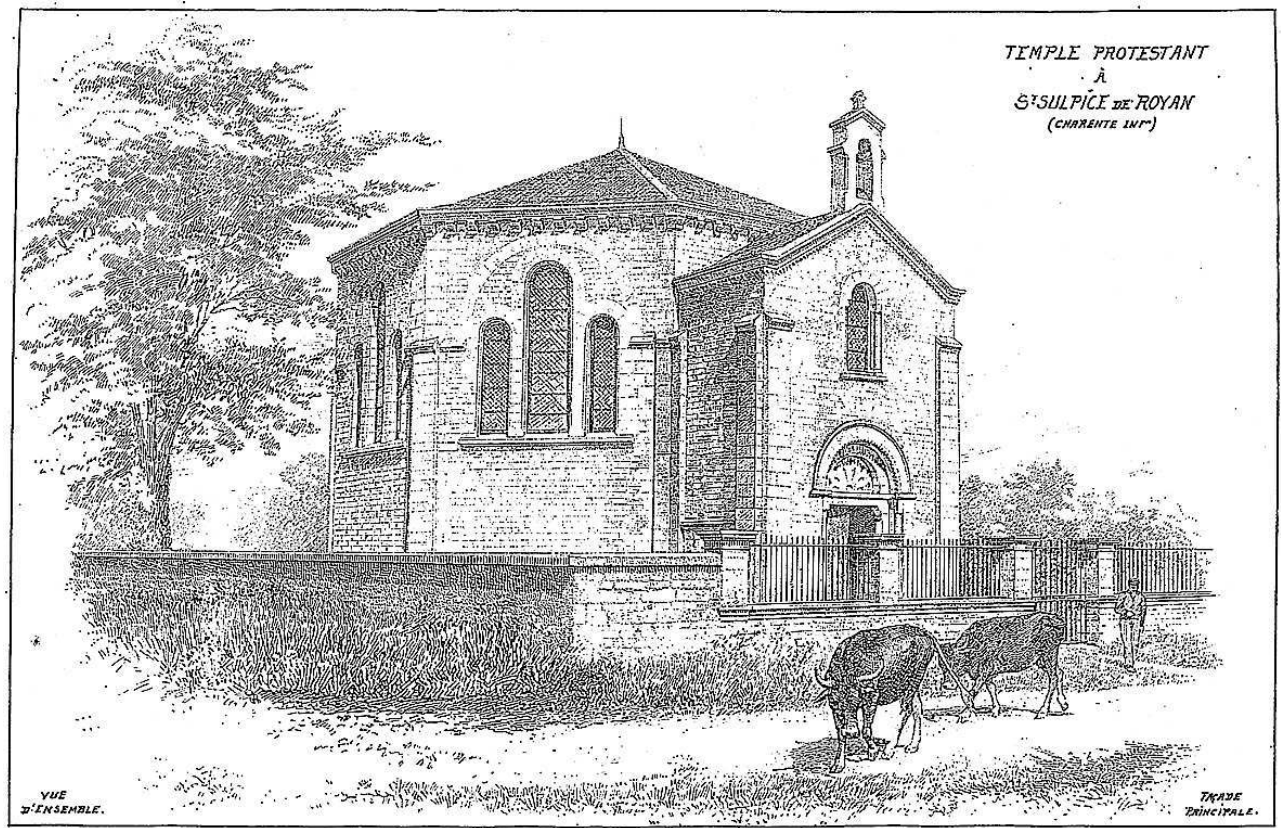

Saint-Sulpice-de-Royan (Charente-Maritime). Temple. Élévation, extrait de Raguenet, A.

MONOgRAPHIES DE BÂTIMENTS MODERNES. 100 numéro, vers 1900

(C) CRMH Poitou-Charentes, 2008

Figure 22

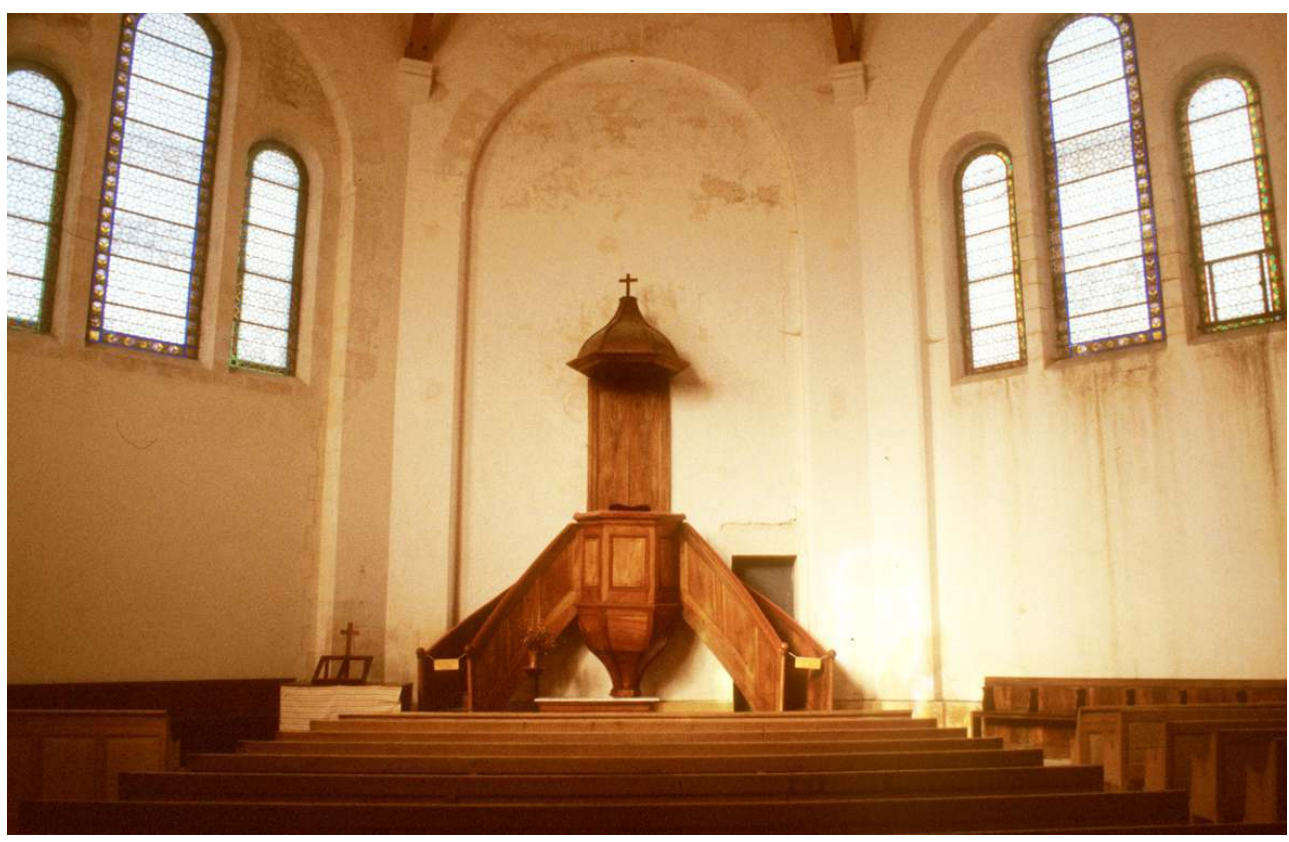

Saint-Sulpice-de-Royan (Charente-Maritime). Temple. Vue intérieure

(c) CRMH Poitou-Charentes, 1998

53 Ce temple est d'une architecture intéressante pour la région: son plan octogonal est unique et son style «néo-roman » innove par rapport à la plupart des temples des deux 
Charentes, principalement classiques. Il a subi très peu de modifications et a conservé son aménagement intérieur initial (fig. $\mathbf{n}^{\circ} \mathbf{2 2}$ ).

\section{Temple de Saintes (Charente-Maritime) ${ }^{31}$. Propriété privée}

La Réforme se manifeste timidement à Saintes, siège épiscopal ; Bernard Palissy fait partie des premiers prédicateurs. Mais dès 1560, les protestants sont si nombreux que le culte est célébré sous la halle. Un temple est édifié vers 1603-1605 (quartier Saint-Vivien) et démoli en 1685. Le second sera, du début du XIX siècle jusqu'à 1906, une petite salle accolée à la chapelle du collège. Le temple actuel, œuvre d'Augustin-Adolf Rey Spitzer (1864-1934), architecte parisien, est inauguré le 27 février 1906. Son plan est rectangulaire, de $13 \mathrm{~m}$ de large sur $19 \mathrm{~m}$ de long, et sa structure est en béton armé. La façade sur rue a reçu un traitement d'inspiration romane, avec porche en avancée et triplets de baies élancées (fig. $\mathbf{n}^{\circ} \mathbf{2 3}$ ). Le décor sculpté, modern style, est très soigné. L'intérieur, enduit d'un plâtre rosé à faux appareil, présente un vaisseau central dont le berceau est percé d'un grand jour zénithal. Les bas-côtés sont couverts en demi-berceaux et surmontés de vastes tribunes voûtées de demi-coupoles. Le mobilier est contemporain de la construction, ainsi que les magnifiques vitraux historiés dus à Félix Gaudin (1851-1930) (fig. $\mathbf{n}^{\circ}$ 24).

Figure 23

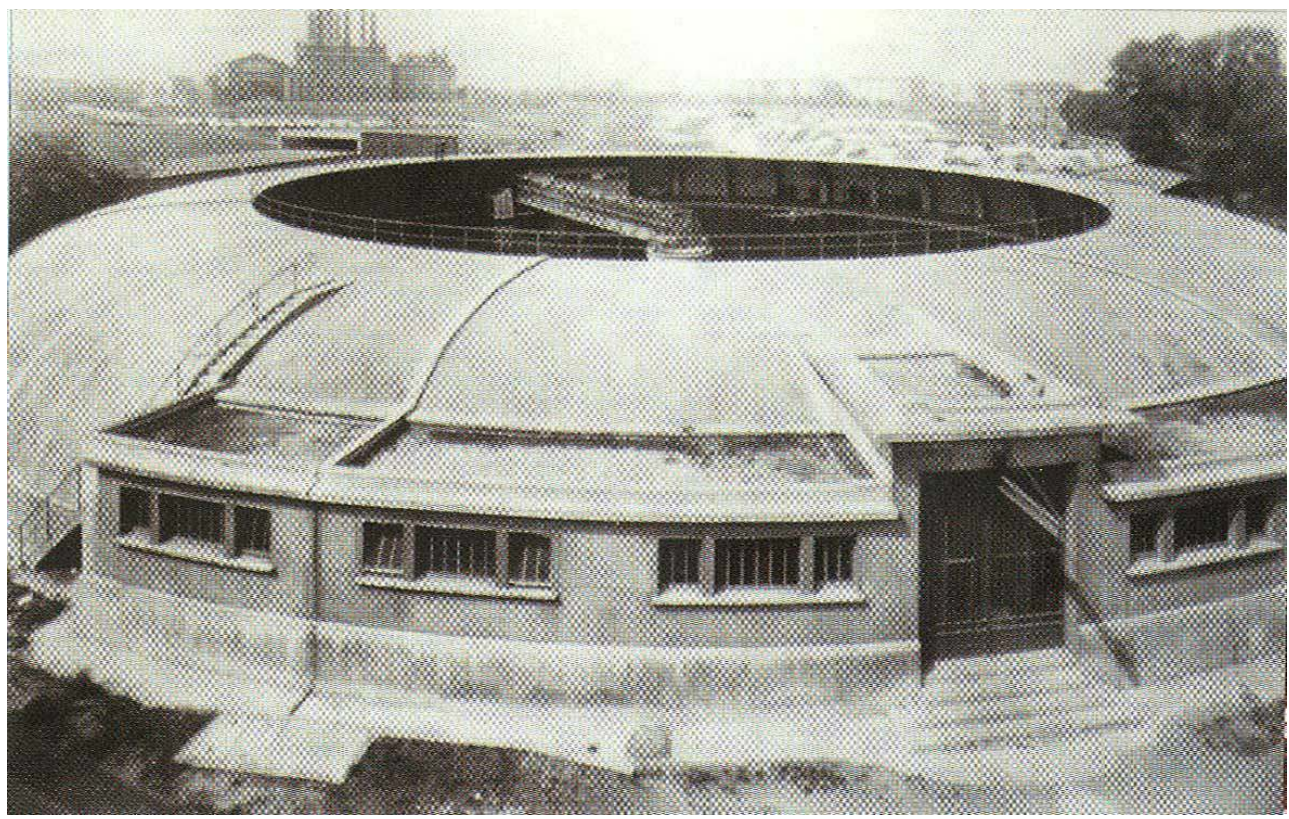

Saintes (Charente-Maritime). Temple. Projet d'Auguste Rey, février, mars 1902, archives de l'église réformée de Saintes

(c) CRMH Poitou-Charentes, 1998 


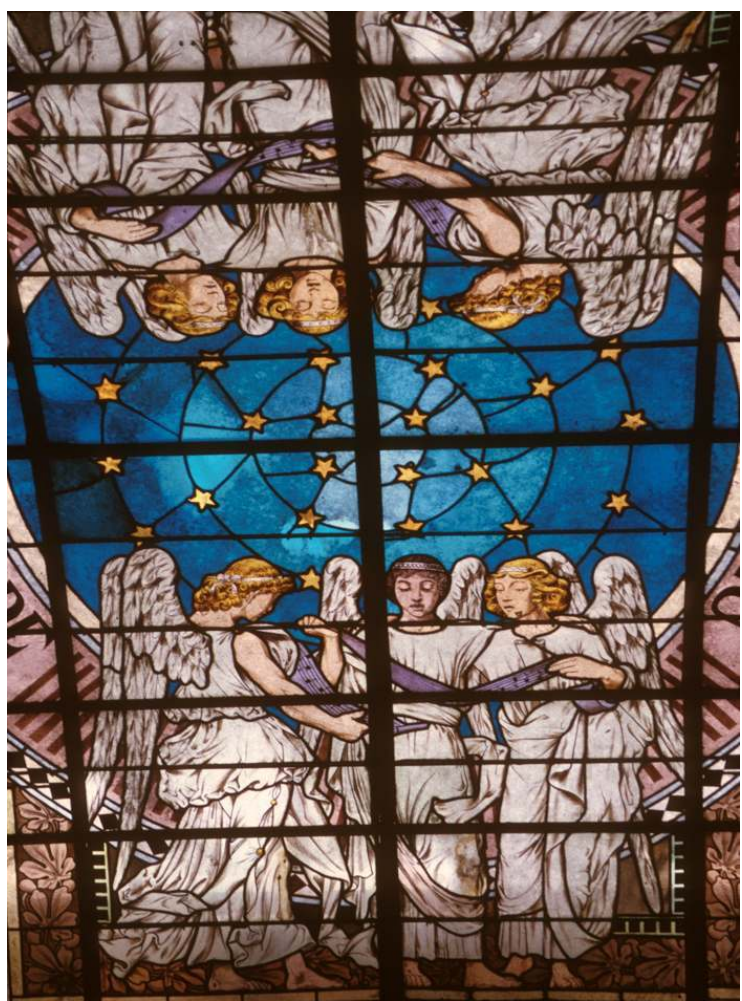

Saintes (Charente-Maritime). Temple. Vitrail zénithal A. Rey, architecte 1905, F. Gaudin peintre verrier (c) CRMH Poitou-Charentes, 1998

Le temple de Saintes, un des derniers bâtis dans la région (en exceptant les temples de la reconstruction), se veut d'un « style roman modernisé ». L'architecte a obtenu un résultat heureux tant dans la façade aux lignes harmonieuses que dans la composition intérieure, gracieuse et fonctionnelle. Les innovations résident dans un décor luxuriant, qui tranche avec l'austérité des édifices du siècle précédent, et dans l'emploi du béton armé.

\section{Temple de Chauray (Deux-Sèvres) ${ }^{32}$. Propriété communale}

Le temple a été construit entre 1853 et 1855 par l'entreprise Bergeron, de La Crèche (Deux-Sèvres), sur les plans de l'architecte Charles-François Chavonet (1804-vers 1858) (fig. $\mathbf{n}^{\circ}$ 25). De plan tréflé, il est constitué d'un corps central carré d'où partent trois absides plus basses à cinq côtés. Le chevet, plat, est épaulé par deux contreforts encadrant une sacristie. Deux porches à arcades plein cintre s'inscrivent dans les angles des absides. Les couvertures indépendantes de chaque corps de bâtiment sont en tuile creuse, les maçonneries sont en moellons assisés apparents et pierre de taille. Désaffecté depuis plusieurs années, il accueille maintenant un centre culturel (fig. $\mathbf{n}^{\circ} \mathbf{2 6}$ ). 
Figure 25
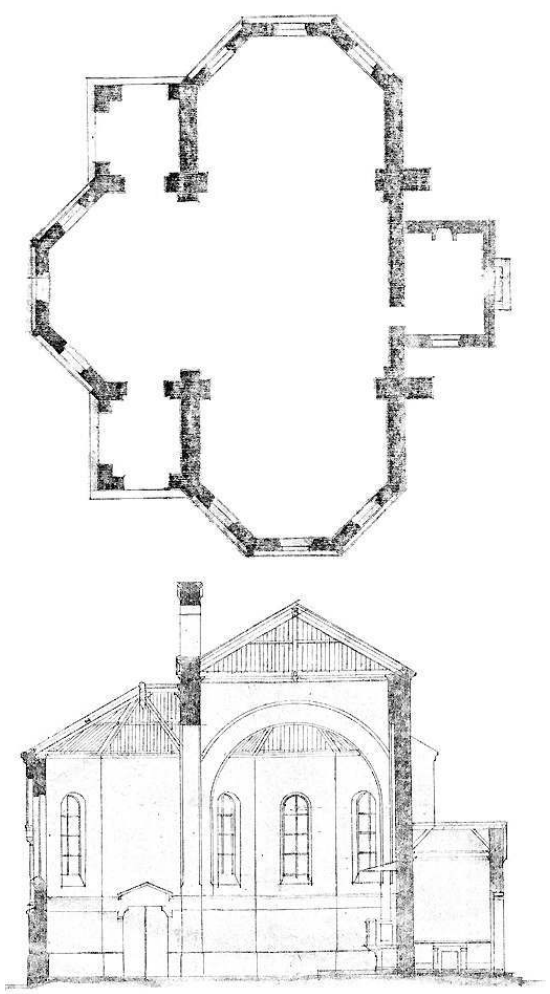

Chauray (Deux-Sèvres). Temple. Plan et coupe de l'architecte Chavonet, 1855, AD 7920724

(c) CRMH Poitou-Charentes, 2008

Figure 26

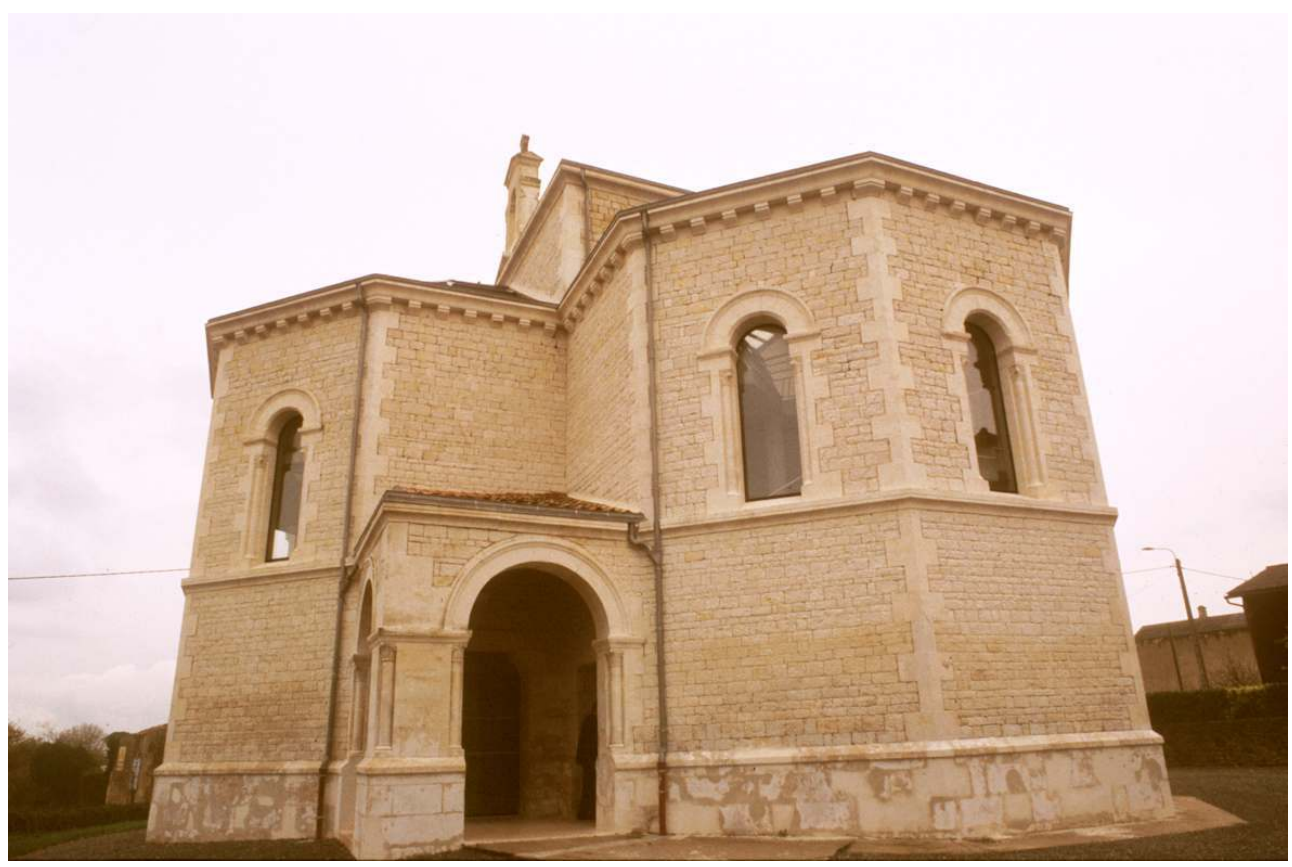

Chauray (Deux-Sèvres). Temple. Vue extérieure

(c) CRMH Poitou-Charentes, 1990 


\section{Temple de Chenay (Deux-Sèvres) ${ }^{33}$. Propriété communale}

Depuis l'Ancien Régime, la population, majoritairement protestante, était privée de lieu de culte. C'est l'architecte de Châtellerault d'origine parisienne, Henri-Alexandre Godineau de la Bretonnerie (1810-vers 1885), qui est l'auteur des plans du temple construit entre 1865 et 1867 par l'entreprise Melin (fig. $\mathbf{n}^{\circ}$ 27). De nombreuses modifications sont apportées au projet initial pour aboutir à un édifice rectangulaire couvert d'une toiture à longs pans en tuile, prolongé par la salle du consistoire et par la base d'un clocher non réalisé contenant l'amorce d'un escalier en vis. Ce temple est surtout remarquable pour son élévation principale avec son portail surmonté d'un oculus percé dans le pignon, évoquant un fronton à base interrompue, ponctué de trois acrotères. La porte en plein cintre avec agrafe centrale, s'ouvre dans une travée corinthienne de pilastres jumelés portant un fronton triangulaire à deux acrotères et une croix axiale. Une bible orne le tympan. Elle est surmontée d'une étoile à six branches et s'ouvre sur des rameaux. On peut y lire « Je suis la lumière du monde ». Faute d'entretien, la toiture du temple s'est effondrée en 1975. Un temps menacé de démolition, il a finalement été restauré et aménagé en 1982 en "maison pour tous », servant toujours à l'occasion au culte protestant (fig. $\mathbf{n}^{\circ} \mathbf{2 8}$ ).

Figure 27

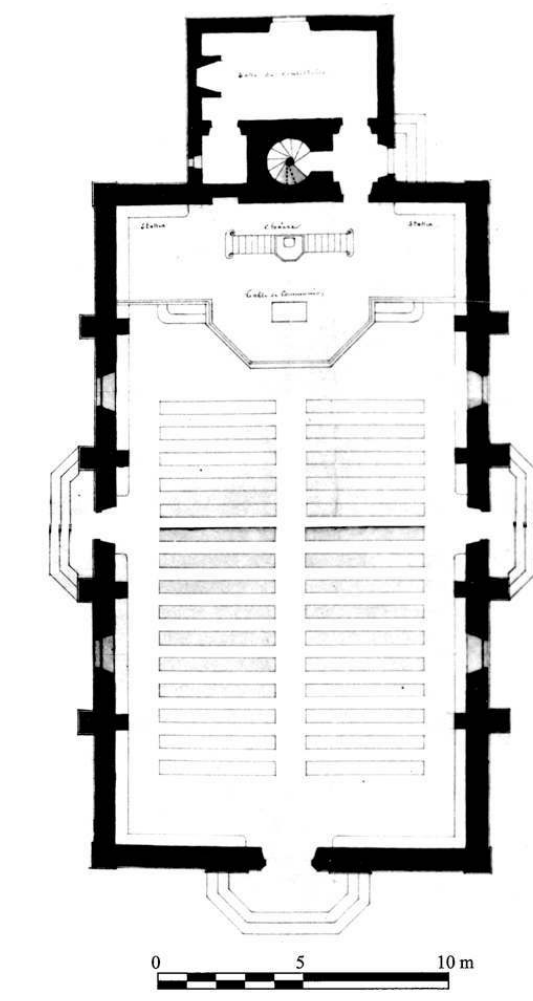

Chenay (Deux-Sèvres). Temple. Projet d'un temple à construire dans la commune de Chenay, plan vers 1858, H. Godineau de la Bretonnerie architecte, AD 79

(c) CRMH Poitou-Charentes, 2008 


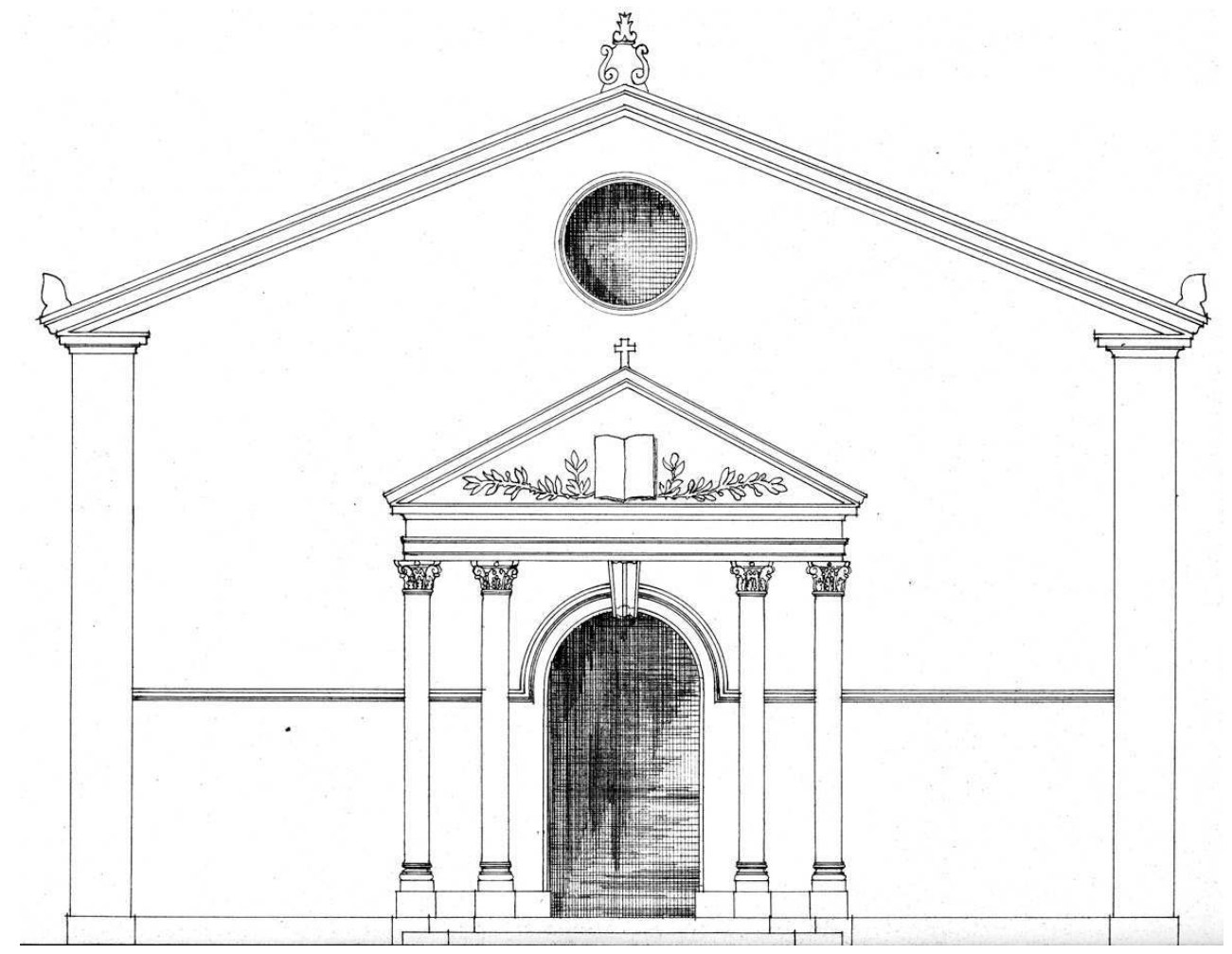

Chenay (Deux-Sèvres). Temple. Relevé de la façade, SDAP 79

(c) CRMH Poitou-Charentes, 2008

\section{Temple de Saint-Gelais (Deux-Sèvres) ${ }^{34}$. Propriété communale}




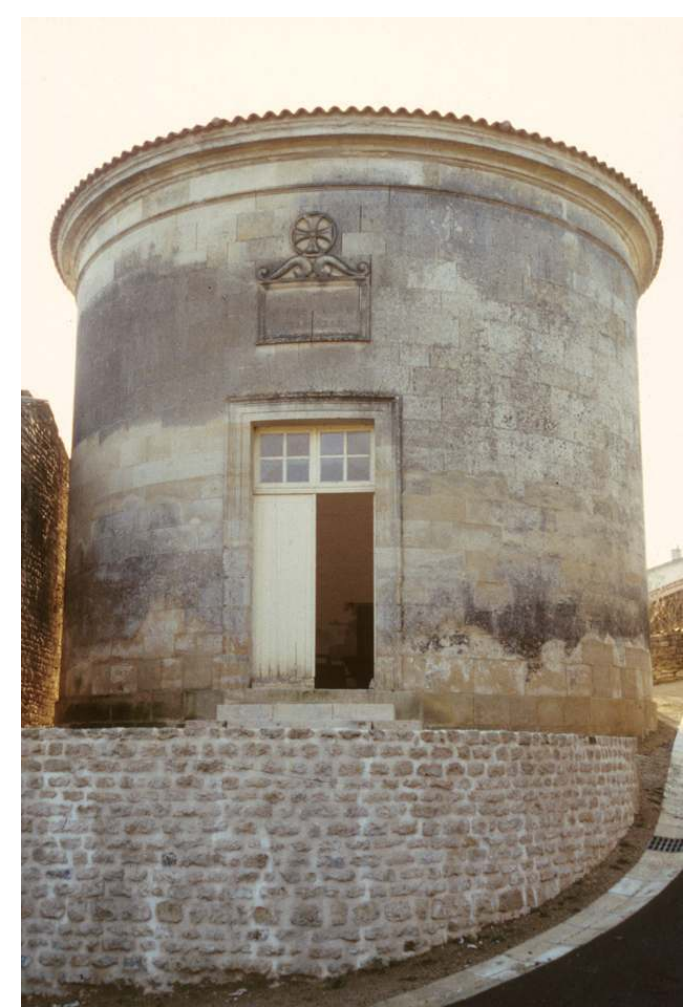

Saint-Gelais (Deux-Sèvres). Temple. Vue extérieure

(c) $\mathrm{CRMH}$ Poitou-Charentes, 1998

C'est sur un terrain en pente, entre le château, ancien fief huguenot, et l'église, que la commune fait construire un temple en 1845. L'architecte Charles-François Chavonet (1804-vers 1858) (voir plus haut) en établit les plans. Il a la forme d'une rotonde de 7,50 m de diamètre intérieur, haute de 7,60 m, l'épaisseur des murs est de 0,70 m. Il est doté d'une sacristie rectangulaire avec fenêtre et cheminée et est recouvert d'une coupole hémisphérique en brique et plâtre, ouverte d'une lunette avec châssis vitré. L'entreprise Aubert de Niort obtient le marché et il faudra remédier à divers défauts de mise en œuvre. Construit en bel appareil de pierre de taille, ce temple a pour seul décor un cartouche au dessus de la porte, sommé de deux volutes et d'une croix huguenote dans lequel on peut lire: "Celui qui croit au Fils a la vie éternelle». Seul temple de plan circulaire de la région, il obéit parfaitement aux règles de sobriété et de rigueur de l'architecture protestante. L'intérieur est cependant assez remarquable en raison de la qualité de l'éclairage zénithal irradié depuis la coupole. Ici, tout est orienté vers le centre où s'accomplit le service divin. (fig. $n^{\circ} 29$ )

\section{Temple de Souvigné (Deux-Sèvres) ${ }^{35}$. Propriété communale}

59 Le temple de Souvigné est construit en partie sur l'emplacement de l'église priorale qui servait au culte protestant depuis la Révolution. Bâti entre 1866 et 1870 par l'entreprise Brothier sur les plans de l'architecte Auguste Bergeron de La Crèche (1833-1912), il offre de grandes similitudes avec celui de Chauray. L'architecte dessine également le mobilier exécuté par Pierre Garnier, menuisier. En 1949, le porche d'entrée ouest est démoli sur les 
conseils d'André Panou, couvreur. Cela provoque de graves désordres dans les maçonneries et les voûtes donnant lieu à d'importants travaux en 1995 sous la conduite de M. Hannebert, architecte des bâtiments de France, et confiés à l'entreprise Somebat. Le temple ne sert plus au culte qu'épisodiquement. De plan tréflé, ses différents éléments sont recouverts d'une toiture en ardoise (fig. $\mathbf{n}^{\circ} \mathbf{3 0}$ ). Il est composé d'un carré ouvert sur trois de ses côtés - nord, est et ouest - sur des absides. Le vaisseau est couvert d'une voûte en pendentifs en brique et en plâtre séparée par des arcs doubleaux reposant sur des colonnes engagées à chapiteaux. Le mobilier - chaire, table de communion, grille et bancs - est toujours en place (fig. $\mathbf{n}^{\circ} \mathbf{3 1}$ ).

Figure 30
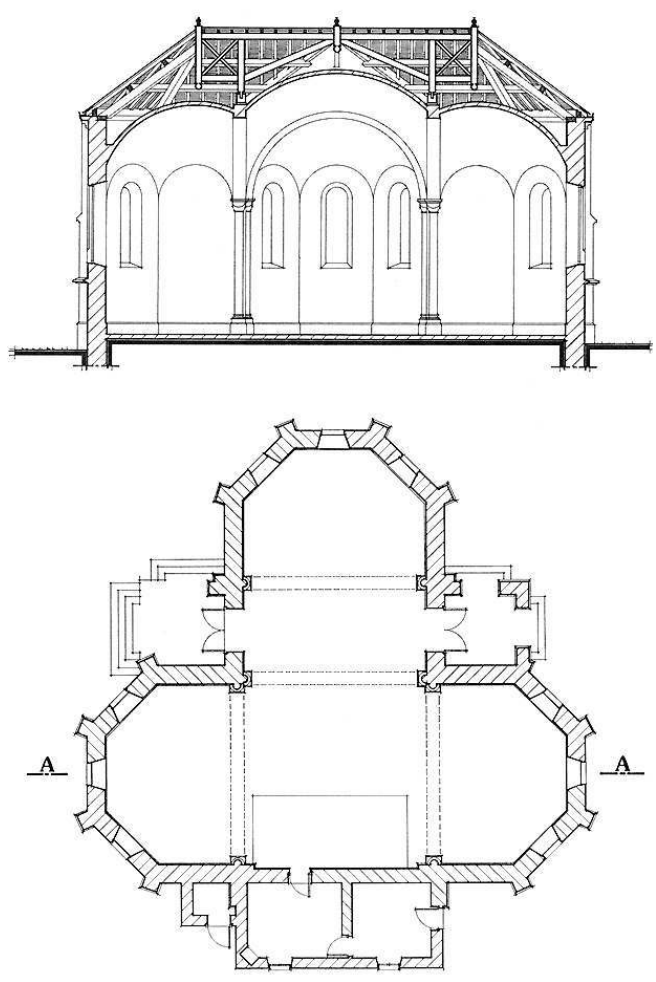

Souvigné (Deux-Sèvres). Temple. Plan du SDAP, Hannebert, 1995

(c) CRMH Poitou-Charentes, 2008 


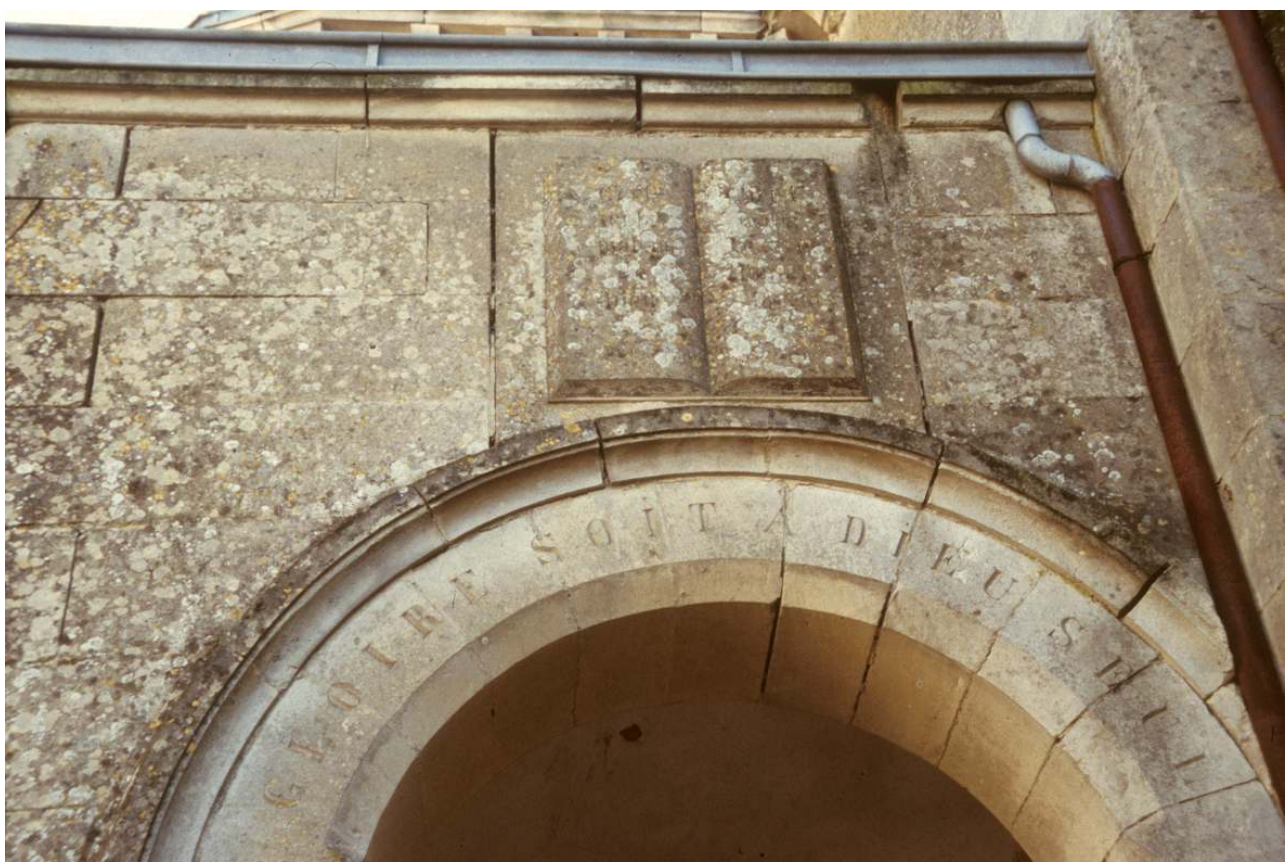

Souvigné (Deux-Sèvres). Temple. Détail du porche d'entrée (c) CRMH Poitou-Charentes, 1998

\section{Temple de Vançais (Deux-Sèvres) ${ }^{36}$. Propriété communale}

Figure 32

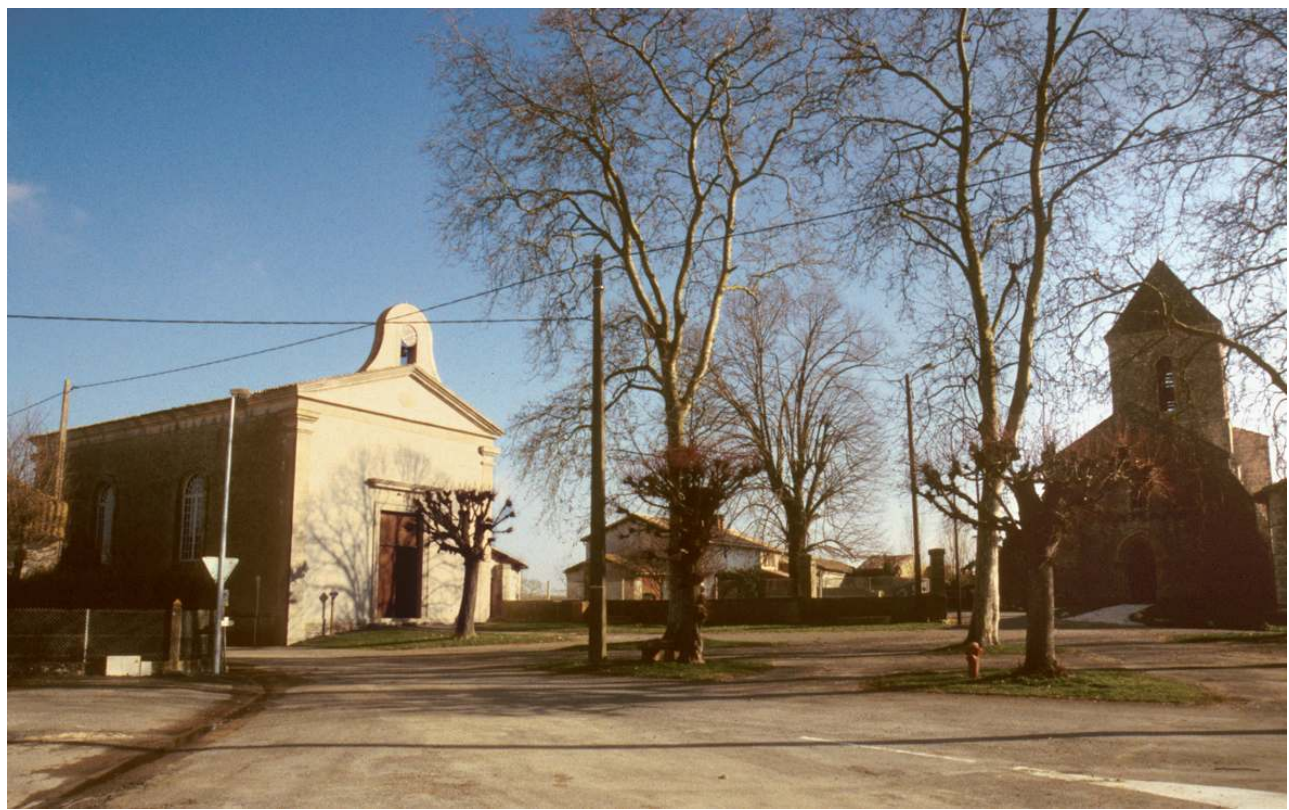

Vançais (Deux-Sèvres). Temple. Vue de la place du village où se côtoient le temple et l'église (c) CRMH Poitou-Charentes, 1998 
Dans un village où l'écrasante majorité des habitants était protestante et où l'église a failli servir au culte réformé, la construction d'un temple, achevé en 1845, a fait figure de symbole. Son emplacement, juste en face de l'église, en témoigne encore, de même que la mise en place d'une horloge sur le temple en 1906 et non pas sur l'église. De plan rectangulaire très simple, avec une sacristie en hémicycle sur son élévation nord, le temple de Vançais a été construit dans le style néo-classique à l'instar de nombreux autres temples de la région. Son auteur est l'architecte Antoine Bizard (vers 1797-1870) à qui l'on doit aussi les temples de Pamproux ${ }^{37}$, Melle $^{38}$, Fressines ${ }^{39}$, Exoudun ${ }^{40}$, Prailles, Rom ${ }^{41}$, $\mathrm{Chey}^{42}$ et Chail ${ }^{43}$. Par sa place en plein cœur du village, ce temple manifeste la prégnance de la population protestante, si profondément ancrée dans ce secteur des Deux-Sèvres (fig. $n^{\circ} 32$ ).

\section{Temple de Rouillé (Vienne) ${ }^{44}$. Propriété communale}

61 L'histoire du protestantisme à Rouillé est particulièrement riche, l'action des pasteurs ayant eu une forte influence, notamment dans l'éducation des jeunes enfants. Après avoir utilisé l'église pendant la Révolution, puis perdu leur lieu de culte, les protestants occupent la grange dîmière jusqu'en 1877. Évoquée dès 1820, la construction d'un nouveau bâtiment a finalement lieu entre 1881 et 1885 et est confiée à Eugène Boyer (vers 1833-1909), architecte départemental (entreprise Félineau et Riffault d'Angoulême) (fig. $\mathbf{n}$ - 33). Le programme, très complet, s'achève par la construction des murs de clôture, de la sacristie, des closets et de la grille sur rue, par la sculpture (Dumas de Niort) et par la confection du mobilier (Robin, ébéniste à Poitiers). Des travaux de consolidation des voûtes sont menés par l'architecte Gallot de Civray en 1963/68, une porte centrale et des vitraux sont installés en 1963/67. 
Figure 33
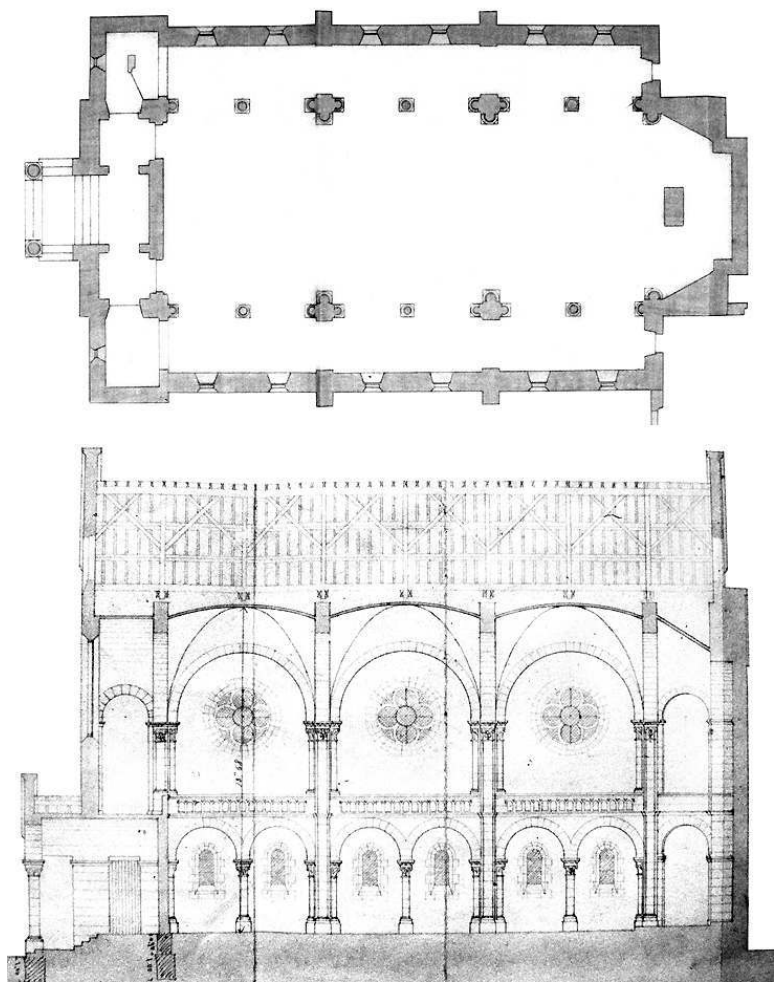

Rouillé (Vienne). Temple. Plan et coupe par É. Boyer, 1877, archives communales de Rouillé

(C) CRMH Poitou-Charentes, 2008 
Figure 34

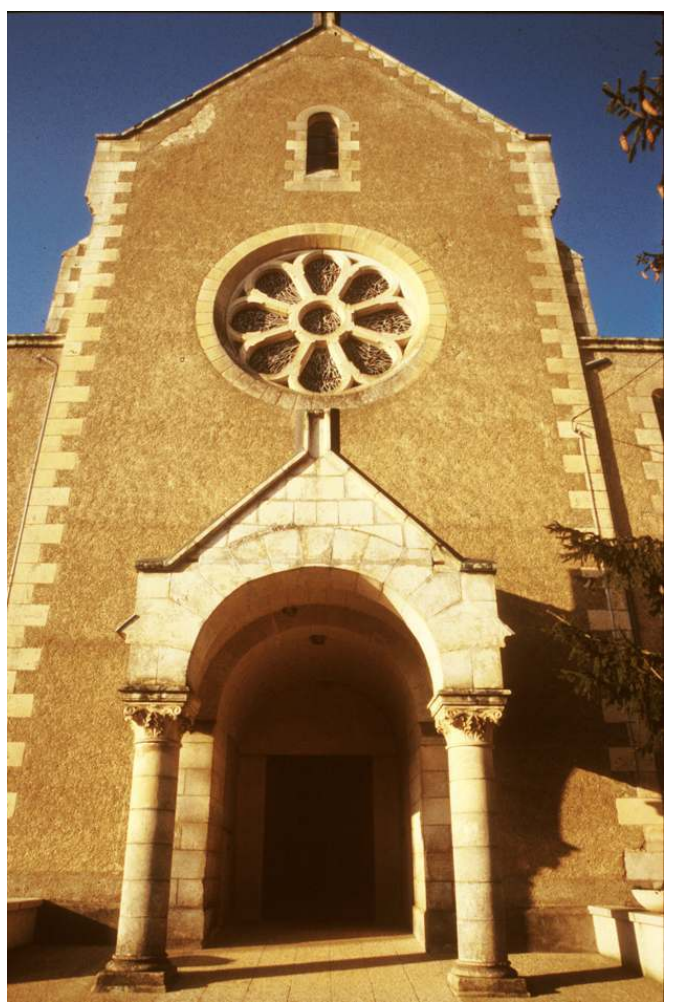

Rouillé (Vienne). Temple. Vue intérieure

(C) CRMH Poitou-Charentes, 1998

Enfin en 1995, le temple est doté d'un orgue placé sur la chaire à prêcher. Il est constitué de plusieurs volumes formant divers décrochements sous pignons découverts et toitures indépendantes en ardoise abritant un porche, deux tours d'accès aux tribunes, deux bascôtés et un corps central. Le vaisseau central et les bas-côtés du temple sont divisés en trois travées ponctuées de colonnes sur dosserets. Le vaisseau central est couvert de voûtes d'arêtes; il s'ouvre entre chaque colonne de doubles arcatures en plein cintre retombant sur une colonne centrale aux chapiteaux feuillagés sur les bas-côtés, supportant des tribunes à l'étage voûtées de berceaux plein cintre transversaux. Le chœur s'inscrit dans une voûte en cul-de-four. Seul temple inscrit monument historique de la Vienne, le temple de Rouillé a un caractère monumental remarquable qui lui a valu l'appellation de «cathédrale protestante du Poitou». Alliance de deux styles, néogothique à l'extérieur et néo-roman à l'intérieur, il est des plus complexes tant dans ses formes que dans son parti architectural (fig. $\mathbf{n}^{\circ} \mathbf{3 4}$ ). 


\section{NOTES DE FIN}

1. Pour l'histoire du protestantisme dans la région voir notamment : Benoist, André. Catholiques et protestants en Moyen-Poitou jusqu'à la Révocation de l'Édit de Nantes (1534-1685), dans Bulletin de la société historique et scientifique des Deux-Sèvres, 2e série, tome XVI, $n^{\circ} 2-3$, 1983 ; Carluer, J.-Yves et Poton, Didier. Les protestants de l'Ouest en 30 questions. La Crèche : Geste Editions, 2007 ; Crete, Liliane. La vie quotidienne à La Rochelle au temps du Grand siège 1627-1628. Paris : Hachette, 1987 ; Delage, Gabriel. Protestants de l'Angoumois au temps des persécutions. Paris, Bruno Sepulchre, 1985 ; Dez, Pierre. Histoire des protestants et de l'église réformée de l'île de Ré. La Rochelle, 1936 ; Dez, Pierre. Histoire des protestants et des églises réformées du Poitou. La Rochelle: Imprimerie de l'ouest, 1936, 3 volumes; Dubief, Henri et Poujol, Jacques. La France protestante, histoire et lieux de mémoire. Paris : Les Editions de Paris, 1996 ; Lebaud-David, Jacques. La Rochelle protestante du XVI ${ }^{\mathrm{e}}$ siècle à nos jours. Edition «La Rochelle 1573 », 1989 ; Mours, Samuel. Les églises réformées en France. Paris : Librairie protestante, 1958; Rivierre, Jean. La vie des protestants du Poitou après la Révocation (1685-1700), dans Bulletin de la société historique et scientifique des Deux-Sèvres, 2e série, tome VI, $\mathrm{n}^{\circ} 4,1973$; Rivierre, Jean. La vie des protestants du Poitou après la Révocation (1685-1700), 2e partie : Les Assemblées de la fin du siècle, dans Bulletin de la société historique et scientifique des Deux-Sèvres, 2e série, tome IX, $n^{\circ} 1,1976$; L'histoire du Poitou protestant. Groupe de recherches historiques de la Maison du protestantisme poitevin, La Couarde. On peut également consulter le site http://www.museeprotestant.org.

2. Cette lacune a été comblée par la parution de l'ouvrage du service régional de l'inventaire: Pons-Willemsen, Charlotte. Le patrimoine protestant, témoignage de quatre siècles de fidélité. Dans Patrimoine de Poitou-Charentes. Inventaire général, ADAGP, C.P.P.P.C, Poitiers, 1998.

3. D'après l'intervention à la commission régionale de Mme Nicole Vray, docteur ès lettres, responsable du musée protestant de La Rochelle. Elle a notamment publié Protestants de l'Ouest . Poitiers : Ed. Ouest-France, 1993 ; Monsieur Monod. Paris : Actes Sud, 1994 ; La Guerre des religions dans la France de l'ouest. La Crèche : Geste éditions, 1997 ; Catherine de Parthenay, duchesse de Rohan. Paris: Perrin, 1998; Protestants en Aunis Saintonge au $19^{\mathrm{e}}$ siècle. Collection Histoire. Paris : Être et connaître, 2006.

4. Carluer, J.-Yves et Poton, Didier. Les protestants de l'Ouest en 30 questions. La Crèche : Geste Editions, 2007.

5. Le temple de Segonzac fut détruit vers 1682, celui de Villefagnan en 1683 et de Jarnac en 1684.

6. Delamain, Robert. Notes sur la vie du protestantisme dans la région de Jarnac, Cognac, Segonzac. 1947.

7. Raby, Claude. Mémoire sur le protestantisme et les temples de Segonzac. Segonzac, 1998.

8. Sautter, Louise. L'évangile à Villefagnan, dans Les cahiers de l'évangélisation. Paris : Société centrale évangélique, 1928.

9. Voir dans la base Mérimée: notice IA00042200. Voir dans la base Mémoire: image IVR54_98160400XA.

10. Jouannet, Gérard. Le Protestantisme à Lignières-Sonneville : du XVI ${ }^{\mathrm{e}}$ siècle au XVIII siècle. Foyer rural de Lignières-Sonneville, 1982.

11. Les tentatives du service des monuments historiques pour approcher les propriétaires de ces maisons se sont soldées par des échecs. Cependant, le temple de Jarnac, constitué de la maison d'oraison construite en 1761 est inscrit au titre des monuments historiques. 
12. Mme Joanne, historienne, a écrit dans plusieurs ouvrages collectifs dont l'Histoire des protestants charentais. Croît vif, 2000 ; pasteur adjoint de Barbezieux et vice-présidente du conseil régional de l'église réformée de France (région Ouest), elle est l'auteur du catalogue de l'exposition: Les Protestants de Barbezieux et de la région, 1985. Extrait de son intervention à la COREPHAE du 27 mai 1998.

13. Voir dans la base Mérimée: notice PA00105147. Voir dans la base Mémoire: image IVR54_20021703273, image IVR54_87170419V.

14. Voir dans la base Mérimée: notice IA79000873. Voir dans la base Mémoire: image IVR54_047902021NUCA, image IVR54_047902191VA, image IVR54_047902079NUCA.

15. Voir dans la base Mérimée: notice PA17000017. Voir dans la base Mémoire: notice IVR54_98171164VA.

16. Voir dans la base Palissy : notice PM17000603.

17. $\mathrm{Au} 27$ juillet 2008, la base Mérimée http://www.culture.gouv.fr/culture/inventai/ patrimoine/, (onglet architecture) recense 115 temples protégés dont 35 en Alsace, 11 en Languedoc-Roussillon, 7 en Rhône-Alpes, 5 en Midi-Pyrénées, etc.

18. Voir dans la base Mémoire : image IVR54_967900888V, image IVR54_967900890V, image IVR54_967900889V.

19. Voir dans la base Mérimée: notice IA00066071. Voir dans la base Mémoire: image IVR54_87790643V, image IVR54_87790644V

20. Voir dans base Mérimée: notice IA00065995. Voir dans la base Mémoire: image IVR54_98790189X, image IVR54_98790186X.

21. Ces notices ont été publiées dans la revue Le courrier du musée protestant de La Rochelle, $\mathrm{n}^{\circ} 2$, 1999. Leurs sources communes sont les dossiers de protection consultables à la Direction régionale des affaires culturelles de Poitou-Charentes.

22. Voir dans la base Mérimée: notice IA00042708, notice PA16000013. Voir dans la base Mémoire : image IVR54_98160047VA.

23. Voir dans la base Mérimée : notice PA16000012.

24. Voir dans la base Mérimée: notice IA00052880. Voir dans la base Mémoire: image IVR54_88160701V.

25. Voir dans la base Mérimée : notice PA16000010.

26. Voir dans la base Mérimée : notice PA17000017.

27. Voir dans la base Mémoire : image IVR54_98171164VA.

28. Voir dans la base Mérimée : PA17000019.

29. Voir dans la base Mérimée : notice PA17000052.

30. Voir dans la base Mérimée : notice PA17000018.

31. Voir dans la base Mérimée: notice PA17000020. Voir dans la base Mémoire: image IVR54_98171061VA.

32. Voir dans la base Mérimée : notice PA00101215.

33. Voir dans la base Mérimée: notice PA79000012. Voir dans la base Mémoire: image IVR54_84790334V, image IVR54_84790333V, image IVR54_95790401V.

34. Voir dans la base Mérimée : notice PA79000014.

35. Voir dans la base Mérimée : notice PA79000016.

36. Voir dans la base Mérimée: notice IA79000691. Voir dans la base Mémoire: image IVR54_83790293V, image IVR54_83790296V.

37. Voir dans la base Mérimée: notice IA00065883. Voir dans la base Mémoire: image IVR54_73790606V.

38. Voir dans la base Mérimée: notice IA00076234. Voir dans la base Mémoire: image IVR54_91791571V.

39. Voir dans la base Mérimée : notice IA79002969. 
40. Voir dans la base Mérimée: notice IA00065995. Voir dans la base Mémoire: image IVR54_98790189X, image IVR54_98790186X.

41. Voir dans la base Mérimée : notice IA79000433.

42. Voir dans la base Mérimée : notice IA79000356.

43. Voir dans la base Mérimée : notice IA79000060.

44. Voir dans la base Mérimée : notice PA86000009.

\section{RÉSUMÉS}

La faible représentativité des temples protestants dans la liste des monuments historiques a conduit la conservation régionale des monuments historiques de Poitou-Charentes à proposer la protection des temples les plus représentatifs parmi les 130 que compte la région: 58 en Charente-Maritime, 40 en Deux-Sèvres, 24 en Charente et 8 dans la Vienne. La qualité architecturale, leur place dans l'histoire, l'affectation au culte, l'intégration dans le paysage urbain, la présence de mobilier et la place de l'édifice en tant que lieu de mémoire ont servi de critères d'analyse. L'histoire et l'architecture des temples protégés des $\mathrm{XIX}^{\mathrm{e}}$ et $\mathrm{XX}^{\mathrm{e}}$ siècles s'inscrivent dans le contexte particulier et mouvementé de l'implantation du culte protestant dans la région.

The examination of the lists of protected historic monuments in the Poitou-Charentes region underlined the poor representation in these lists of Protestant temples. This fact incited the historic monuments service of the region to put forward a more representative selection of the 130 Protestant temples to be found in the region, 58 in the Charente-Maritime department, 40 in the Deux-Sèvres, 24 in Charente and 8 in the Vienne. The criteria adopted to analyse these temples included their architectural qualities, their place in history, their use by the Protestant faiths, their integration into their urban environment, the presence of interesting church furnishings and the possible role of the temple as a place of memory. The history and the architecture of these temples during the 19th and 20th centuries are to be understood in the particular and animated context of the arrival of Protestantism in the region. 


\section{INDEX}

Keywords : Poitou-Saintonge Protestant Association, Pastor Picanon, Rousseau family, Protestant temples in the Poitou-Charentes region, Protestant temples protected as historic monuments, Protected Protestant temples, Protestantism in the Poitou-Charentes region, Protestant heritage, 19th-century temples, Protestant liturgical furnishing, Neo-Classical, NeoMedieval, Edict of Nantes, Revocation of the Edict of Nantes, Edict of tolerance, Arvert peninsula, Houses of prayer, Jarnac house of prayer, Jarnac temple, Segonzac house of prayer, Segonzac temple, Chez Piet house of prayer at Lignières-Sonneville, Temple of Saint-Sulpice-de-Royan, Saint-Gelais temple, Récollets convent of La Rochelle, Temple of La Rochelle, Beaussais church, Beaussais temple, Cressac church, Cressais temple, Chauray temple, Chênaie cemetery at Breuillet, Cozes temple, Tapestries of the tables of law at the Marsilly temple, Temple of Verrines-sous-Celles, Vançais temple, Saintes temple, Chenay temple, Villefagnan temple, Souvigné temple, Pons temple, Saint-Martin de Pons church, L'Eguille temple, La Couarde temple, Exoudun temple, Royan temple, Récollets chapel of Pons, Saintes temple, Pamproux temple, Melle temple, Fressines temple, Prailles temple, Rom temple, Chey temple, Chail temple Mots-clés : M. Hannebert, Gallot de Civray, Félix Gaudin, Pierre Garnier, Dumas, Robin, M. Guesdon, famille Rousseau, Jean Moindron, pasteur Picanon, Bernard Palissy, association PoitouSaintonge-Protestants, Jean Ranson de Bois-Blanchard, Alphonse Demenieux, Paul Abadie, François Nicolas Pineau, Albert Cochot, René Baraton, Jean Bauhain, Marc Hébrard, Alain Bourbonnais, Léon Jossier, Augustin-Adolf Rey Spitzer, Charles-François Chavonet, HenriAlexandre Godineau de la Bretonnerie, Auguste Bergeron de La Crèche, Antoine Bizard, Eugène Boyer, J. Morel, maison d'oraison de Jarnac, temple de Jarnac, maison d'oraison de Segonzac, temple de Segonzac, maison d'oraison Chez Piet à Lignières Sonneville, temple de Saint-Sulpicede-Royan, temple de Saint-Gelais, couvent des Récollets de La Rochelle, temple de La Rochelle, église de Beaussais, temple de Beaussais, église de Cressac, temple de Cressac, temple de Chauray, cimetière de la Chênaie à Breuillet, temple de Cozes, tapisserie des tables de la loi du temple de Marsilly, temple de Verrines-sous-Celles, temple de Vançais, temple de Saintes, temple de Chenay, temple de Villefagnan, temple de Souvigné, temple de Pons, église Saint-Martin de Pons, temple de l'Éguille, temple de La Couarde, temple d'Exoudun, temple de Royan, chapelle des Récollets de Pons, temple de Saintes, temple de Pamproux, temple de Melle, temple de Fressines, temple de Prailles, temple de Rom, temple de Chey, temple de Chail, Temples protestants en Poitou-Charentes, temples protestants monuments historiques, temples protestants protégés, protestantisme en Poitou-Charentes, patrimoine protestant, temples du XIXe siècle, agencement liturgique protestant, néoclassicisme, néomédiéval, édit de Nantes, révocation de l'édit de Nantes, édit de tolérance, Moncoutant, presqu'île d'Arvert, La Rochelle, Nantes, maisons d'oraison

\section{AUTEURS}

\section{BRIGITTE MONTAGNE}

Documentaliste recenseur à la conservation régionale des monuments historiques, Direction régionale des affaires culturelles de Poitou-Charentes. brigitte.montagne@culture.gouv.fr 


\section{YANNICK COMTE}

Documentaliste recenseur à la conservation régionale des monuments historiques, Direction régionale des affaires culturelles de Poitou-Charentes. yannick.comte@culture.gouv.fr

\section{CATHERINE TIJOU}

Documentaliste recenseur à la conservation régionale des monuments historiques, Direction régionale des affaires culturelles de Poitou-Charentes 